\title{
Delineation of motoneuron subgroups supplying individual eye muscles in the human oculomotor nucleus
}

\author{
Emmanuel Che Ngwa ${ }^{1+}$, Christina Zeeh ${ }^{1,2}$, Ahmed Messoudi ${ }^{1}$, Jean A. Büttner-Ennever ${ }^{1}$ \\ and Anja K. E. Horn ${ }^{1,2}$ *
}

${ }^{1}$ Oculomotor Group, Institute of Anatomy and Cell Biology, Department I, Ludwig-Maximilians-University of Munich, Munich, Germany

${ }_{2}^{2}$ German Center for Vertigo and Balance Disorders, Ludwig-Maximilians-University of Munich, Munich, Germany

\section{Edited by:}

Paul J. May, University of Mississippi Medical Center, USA

\section{Reviewed by:}

Joan S. Baizer, University of Buffalo, USA

Fiorenzo Conti, Università Politecnica delle Marche, Italy

L. Craig Evinger, Stony Brook

University, USA

${ }^{*}$ Correspondence:

Anja K. E. Horn, Oculomotor Group, Institute of Anatomy and Cell Biology, Department I, Ludwig-MaximiliansUniversity of Munich,

Pettenkoferstrasse 11, D-80336

Munich, Germany

e-mail:anja.bochtler@med.

uni-muenchen.de

${ }^{\dagger}$ Present address:

Emmanuel Che Ngwa, Medizinische Klinik I, Klinikum Fulda $A G$,

Pacelliallee 4, 36043 Fulda, Germany
The oculomotor nucleus (nIII) contains the motoneurons of medial, inferior, and superior recti (MR, IR, and SR), inferior oblique (IO), and levator palpebrae (LP) muscles. The delineation of motoneuron subgroups for each muscle is well-known in monkey, but not in human. We studied the transmitter inputs to human nlll and the trochlear nucleus (nIV), which innervates the superior oblique muscle (SO), to outline individual motoneuron subgroups. Parallel series of sections from human brainstems were immunostained for different markers: choline acetyltransferase combined with glutamate decarboxylase (GAD), calretinin (CR) or glycine receptor. The cytoarchitecture was visualized with cresyl violet, Gallyas staining and expression of non-phosphorylated neurofilaments. Apart from nIV, seven subgroups were delineated in nIII: the central caudal nucleus (CCN), a dorsolateral (DL), dorsomedial (DM), central (CEN), and ventral (VEN) group, the nucleus of Perlia (NP) and the non-preganglionic centrally projecting Edinger-Westphal nucleus (EWcp). DL, VEN, NP, and EWcp were characterized by a strong supply of GAD-positive terminals, in contrast to DM, CEN, and nIV. CR-positive terminals and fibers were confined to CCN, CEN, and NP. Based on location and histochemistry of the motoneuron subgroups in monkey, CEN is considered as the SR and IO motoneurons, DL and VEN as the B- and A-group of MR motoneurons, respectively, and DM as IR motoneurons. A good correlation between monkey and man is seen for the CR input, which labels only motoneurons of eye muscles participating in upgaze (SR, IO, and LP). The CCN contained LP motoneurons, and $\mathrm{nIV}$ those of SO. This study provides a map of the individual subgroups of motoneurons in human nIll for the first time, and suggests that NP may contain upgaze motoneurons. Surprisingly, a strong GABAergic input to human MR motoneurons was discovered, which is not seen in monkey and may indicate a functional oculomotor specialization.

Keywords: central caudal nucleus, nucleus of Perlia, extraocular muscles, motoneurons, calretinin, glycine, GABA, eye movements

\section{INTRODUCTION}

Eye movements are essential for vision, because they direct the fovea to a visual target, and stabilize gaze during locomotion to

Abbreviations: nIII, oculomotor nucleus; nIV, trochlear nucleus; nVI, abducens nucleus; CCN, central caudal nucleus; CEN, central group; ChAT, choline acetyltransferase; CMRF, central mesencephalic reticular formation; CR, calretinin; DL, dorsolateral group; DM, dorsomedial group; DR, dorsal raphe nucleus; EAP, extravidin-peroxidase; EW, Edinger-Westphal nucleus; EWcp, centrally projecting Edinger-Westphal nucleus; EWpg, Edinger-Westphal nucleus containing preganglionic neurons; GABA, gamma-aminobutyric acid; GAD, glutamate decarboxylase; GlyR, glycine receptor; IC, inferior colliculus; INC, interstitial nucleus of Cajal; IO, inferior oblique muscle; IPN, interpeduncular nucleus; IR, inferior rectus muscle; LP, levator palpebrae muscle; LR, lateral rectus muscle; MGB, medial geniculate body; MIF, multiply-innervated non-twitch muscle fibers; ML, medial lemniscus; MLF, medial longitudinal fasciclus; MR, medial rectus muscle; NIII, oculomotor nerve; NP, nucleus of Perlia; NP-NF, non-phosphorylated neurofilaments; PAG, periaqueductal gray; $\mathrm{PB}$, phosphate buffer; PN, pontine nuclei; RIMLF, rostral interstitial nucleus of the medial longitudinal fasciculus; RN, red nucleus; SC, superior colliculus; SCP, superior cerebellar peduncle; SE of mean, standard error of the mean; SIF singly-innervated twitch muscle fibers; $\mathrm{SNc}$, substantia nigra pars compacta; $\mathrm{SNr}$, substantia nigra pars reticulata; SO, superior oblique muscle; SOA, supraoculomotor area; SR, superior rectus muscle; UCN, urocortin; VEN, ventral group. compensate for head and body movements (Leigh and Zee, 2006; Horn and Leigh, 2011). The motor and premotor pathways for several eye movement types, e.g., saccades and the vestibulo-ocular reflex, are well studied in monkey, and they form the basis for assessing the homologous brain structures in humans, for example, in clinical cases of eye movement disorders (Horn and Leigh, 2011; Kennard, 2011). However, different species have different patterns of eye movements, and different arrangements of their oculomotor subgroups (for review: Büttner-Ennever, 2006). In order to analyze the clinical-anatomical studies involving horizontal and vertical, up- or downward eye movements, the knowledge of the localization of the motoneurons of individual extraocular muscles in human is essential. Despite the fact that efforts on this topic have been undertaken since 1897 (Bernheimer, 1897) in human, the current map of individual motoneuronal groups adopted in most textbooks is still that of the monkey (Warwick, 1953a). In non-human primates, the oculomotor nucleus (nIII) and trochlear nucleus (nIV) lie in the mesencephalic tegmentum at the ventral border of the periaquaeductal gray beneath the 
aqueduct (for review: Büttner-Ennever, 2006). Since the classical work on the nIII in rhesus monkey by Warwick (1953a) using degeneration techniques, the topographic map has undergone substantial revisions in the primate using retrograde tract-tracing methods (Büttner-Ennever and Akert, 1981; Porter et al., 1983; Büttner-Ennever et al., 2001; Büttner-Ennever, 2006). Neurons supplying the ipsilateral medial rectus muscle (MR) are distributed into three clusters within nIII: the ventral A-group extending into the medial longitudinal fasciclus (MLF), the dorsolateral B-group and the small C-group at the dorsomedial border of nIII (BüttnerEnnever and Akert, 1981). The motoneurons of the ipsilateral inferior rectus muscle (IR) are located dorsally at rostral levels of the nIII, and the motoneurons of the contralateral superior rectus muscle (SR) and ipsilateral inferior oblique muscle (IO) lie partly intermingled within the central nIII of one side (Spencer and Porter, 1981; Porter et al., 1983). The nIV contains only the motoneurons of the contralateral superior oblique muscle (SO; Porter et al., 1983). In primates, a separate midline nucleus at the transition of nIII and nIV, the central caudal nucleus (CCN), contains the motoneurons of the levator palpebrae (LP) muscle, which elevates the upper eyelid (Porter et al., 1989).

The Edinger-Westphal nucleus (EW) lies immediately dorsal to nIII. It is often included in the term "nIII complex," although it does not contain motoneurons of extraocular muscles. However, recent work has shown that the EW contains different functional cell groups, which must be clearly demarcated from each other and from the nIII proper. In monkey, EW houses the preganglionic (pg) neurons of the ciliary ganglion, in accordance with traditional belief, and is now called EWpg (Horn et al., 2008; May et al., 2008). However, in human, the cytoarchitectural EW represents a cell group of non-pg centrally projecting ( $\mathrm{cp}$ ) neurons that contain urocortin (UCN), and it is therefore now termed EWcp (Horn et al., 2008; Kozicz et al., 2011; Büttner-Ennever and Horn, 2014).

Transmitter content can also distinguish between oculomotor subgroups. Previous studies of transmitter content in cat and monkey have shown that the motoneurons of horizontally moving eye muscles are controlled by glycinergic inputs, whereas those of vertically moving eye muscles by GABAergic afferents (Spencer etal., 1989, 1992; Spencer and Baker, 1992). In addition, more recent reports revealed that only the motoneurons of muscles involved in upgaze, including the LP, are selectively targeted by calretinin (CR)-positive afferents (Ahlfeld et al., 2011; Zeeh etal., 2013); this finding proved very useful in the present study for the recognition of IO and SR motoneurons.

In the experiments reported here, we identified the motoneuron groups of individual eye muscles in human. This was based partly on a comparison with the localization of motoneurons derived from tract-tracing experiments in monkey, and partly on the cytoarchitecture and differential histochemical inputs to motoneuron subgroups revealed by immunocytochemical staining for non-phosphorylated neurofilaments (NP-NF) glutamate decarboxylase (GAD), CR, glycine receptor (GlyR) in human midbrain sections. These groups have also been clearly separated from the EW and the nucleus of Perlia (NP) subgroups, and present a new map of the human oculomotor subgroups. A preliminary version of the map has been published previously (Büttner-Ennever and Horn, 2014).

\section{MATERIALS AND METHODS \\ ANTISERA}

\section{Choline acetyltransferase}

Cholinergic motoneurons were detected with a polyclonal choline acetyltransferase (ChAT) antibody raised in goat (AB144P, Chemicon) against the whole enzyme isolated from human placenta, which is identical to the brain enzyme (Bruce et al., 1985; Table 1). In immunoblots, this antibody recognizes a $68-70 \mathrm{kDa}$ protein. The appearance and distribution of ChAT-positive neurons with this antibody in the present study is identical to the data of previous reports (Ichikawa and Shimizu, 1998).

\section{Non-phosphorylated neurofilaments}

Non-phosphorylated neurofilaments were detected using a mouse monoclonal antibody (IgG1), supplied as a high titer mouse ascites fluid (Table 1). The antibody was raised against homogenized hypothalami recovered from Fischer 344 rats (Sternberger et al., 1982). It reacts with a non-phosphorylated epitope in neurofilament $\mathrm{H}$ and is abolished when the epitope is phosphorylated (clone 02-135; SMI32, Sternberger Monoclonals Inc., Lutherville, MD, USA; Sternberger and Sternberger, 1983). This antibody visualizes two bands (200 and $180 \mathrm{kDa}$ ) in conventional immunoblots (Goldstein et al., 1987).

\section{Glutamic acid decarboxylase}

GABAergic terminals were detected with a monoclonal antibody against the GABA-synthetizing enzyme glutamic acid

Table 1 | Sources and dilutions of primary antibodies.

\begin{tabular}{|c|c|c|c|c|}
\hline Antigen & Antibody & Host & Antibody source & Dilution \\
\hline Choline acetyltransferase (ChAT) & Polyclonal anti-ChAT & Goat & Chemicon, Temecula, CA, USA, AB144P & $1: 100$ \\
\hline Calretinin (CR) & Polyclonal anti-CR & Rabbit & SWant, Bellinzona, Switzerland, 7669/3H & $1: 2500$ \\
\hline Urocortin 1 (UCN) & Polyclonal anti-UCN & Rabbit & Sigma, St. Louis, USA, U4757 & $1: 8000$ \\
\hline GAD & Monoclonal anti-GAD & Mouse & Biotrend, GC3108 & $1: 4000$ \\
\hline$\alpha$ and $\beta$ subunits of glycine receptor (GlyR) & $\begin{array}{l}\text { Monoclonal anti-GlyR } \\
\text { (clone mAb4a) }\end{array}$ & Mouse & $\begin{array}{l}\text { Synaptic Systems, Göttingen, Germany, } 146 \\
011\end{array}$ & $1: 300$ \\
\hline Non-phosphorylated neurofilaments (NP-NF) & Monoclonal anti-NP-NF & Mouse & Sternberger, Lutherville, MD, USA, SMI-32P & $1: 5000$ \\
\hline
\end{tabular}


decarboxylase (GAD; GAD $65 / 67$ GC3108, batch number Z05507, clone 1111, Biotrend, Cologne, Germany; Table 1). Two molecular forms of $\mathrm{GAD}-\mathrm{GAD}_{65}$ and $\mathrm{GAD}_{67}$ - are known from different species. There is $65 \%$ amino acid sequence homology between the two isoforms. Whereas $\mathrm{GAD}_{67}$ is a cytoplasmic protein consisting of 594 amino acid residues, $\mathrm{GAD}_{65}$ is an amphiphilic and membrane anchored protein consisting of 585 amino acid residues. The antibody GC 3108 recognizes a linear epitope at the C-terminus of rat GAD, common to both isoforms. The hybridoma secreting the antibody to $\mathrm{GAD}_{65 / 67}$ was generated by fusion of splenocytes from a mouse immunized with fragments of recombinant human $\mathrm{GAD}_{65}$ fused to glutathione-S-transferase (Ziegler et al., 1996).

\section{Glycine receptor}

The GlyR is a ligand gated $\mathrm{Cl}^{-}$channel, mediating synaptic inhibition in various brain regions. It is a pentamer consisting of $\alpha$ and $\beta$ subunits. In this study, a monoclonal mouse antibody, clone mAb4a (Cat. No. 146011 , Synaptic Systems, Göttingen, Germany), was used, which recognizes the $\alpha$ and $\beta$ subunits of the GlyR (Table 1). This antibody results in stronger labeling compared to antibodies directed against the $\alpha$ subunit only (Pfeiffer et al., 1984; Waldvogel et al., 2010). The GlyR is present in postsynaptic structures and intracellular sites involved in protein synthesis and transport shown by electron microscopy studies, which explains the diffuse immunostaining of neuronal somata and punctate labeling along the membranes of neurons (Triller et al., 1985; Baer et al., 2009).

\section{Calretinin}

A rabbit polyclonal CR antibody (7699/3H, LOT 18299, Swant, Bellinzona, Switzerland) was used to detect CR-containing neuronal profiles (Table 1). CR is a calcium-binding protein of the EF-hand family, related to calbindin D-28k and calmodulin, with a widespread distribution within the brain in different species (Andressen et al., 1993; Baizer and Baker, 2006; Baizer and Broussard, 2010). The CR antiserum is produced in rabbits by immunization with recombinant human CR containing a 6-his tag at the N-terminal.

\section{Urocortin}

For the identification of UCN-containing neurons a polyclonal antibody (Sigma, U-4757; Sigma, St. Louis, USA) was used. It was raised in rabbit using a synthetic peptide corresponding to the Cterminus of human UCN (amino acids 25-40 with N-terminally added lysine), conjugated to keyhole limpet hemocyanin (KLH) as immunogen. The antibody does not cross-react with human or rat corticotrophin releasing factor or human adrenocorticotropic hormone (Bachtell et al., 2003).

\section{HUMAN TISSUE}

The brainstems from seven postmortem human cases (case 1 frozen; cases 2-6 - paraffin embedded) were obtained 24-72 h after death from bodies donated to the Anatomical Institute of the Ludwig-Maximilians-University in accordance with the ethical regulations of the University, and through the Reference Center for Neurodegenerative Disorders of the Ludwig-MaximiliansUniversity with written consent from next of kin, who confirmed the wishes at time of death. All procedures were approved by the
Table 2 | Human post-mortem cases used in the study.

\begin{tabular}{llllll}
\hline Case & Age & Gender & $\begin{array}{l}\text { Post-mortem } \\
\text { delay (hour) }\end{array}$ & $\begin{array}{l}\text { Fixation } \\
\text { duration (day) }\end{array}$ & Cutting \\
\hline 1 & 90 & Female & 24 & 2 & Frozen \\
2 & 69 & Male & 24 & 2 & Paraffin \\
3 & 57 & Female & 24 & 6 & Paraffin \\
4 & 67 & Male & 24 & 10 & Paraffin \\
5 & 75 & Male & 72 & 10 & Paraffin \\
6 & 54 & Female & 24 & 8 & Paraffin \\
\hline
\end{tabular}

Local Research Ethics Committees. The study is in accordance with the ethical standards laid down in the 1964 Declaration of Helsinki. The age of the donators ranged from 54 to 90 years, and there is no history of neurological disease (Table 2). The tissue was immersed either in $4 \%$ paraformaldehyde in $0.1 \mathrm{M}$ phosphate buffer (PB), pH 7.4 , or in $10 \%$ formalin for 7 days. Five brainstems were embedded in paraffin, and from each case serial sections of 5, 10, and $20 \mu \mathrm{m}$ thickness were cut. Sections of $20 \mu \mathrm{m}$ thickness were used for Nissl- and Gallyas fiber staining, 5 and $10 \mu \mathrm{m}$ thick sections were immunostained "on-slide" after deparaffination and rehydrating in distilled water. For freeze cutting, one brainstem (case 1) was equilibrated in increasing concentrations of sucrose in $0.1 \mathrm{M} \mathrm{PB}$ and cut at $40 \mu \mathrm{m}$ using a cryostat. Every sixth frozen section (240 $\mu \mathrm{m}$ interval) was defatted, rehydrated, then stained with $0.5 \%$ cresyl violet for $5 \mathrm{~min}$. In neighboring sections, the myelin was stained with silver using the physical developing method of Gallyas (Gallyas, 1979). The nomenclature and abbreviations for human brainstem structures are in accordance with the revised new edition of Olszewski and Baxter's "cytoarchitecture of the human brainstem” (Büttner-Ennever and Horn, 2014).

\section{Single immunostaining for NP-NF, GAD, CR, UCN}

Parallel series of adjacent frozen sections $(40 \mu \mathrm{m})$ were processed "free-floating," whereas the paraffin sections $(10 \mu \mathrm{m})$ were processed "on-slide" after deparaffination in three changes of xylene and rehydration in decreasing concentration of alcohol (100, $96,90$, and $70 \%)$ and a final rinse in distilled water. In addition, for the paraffin sections of formalin-fixed tissue an antigen retrieval procedure preceded the protocol for immunostaining: after deparaffinizing, the sections were incubated in $0.01 \mathrm{M}$ sodium citrate buffer $(\mathrm{pH} 8.5)$ in a water bath at $80^{\circ} \mathrm{C}$ for $15 \mathrm{~min}$, and then for another $15 \mathrm{~min}$ at room temperature, before being rinsed and started with the immunostaining protocol (Jiao et al., 1999).

After a short rinse in double distilled water and $0.1 \mathrm{M} \mathrm{PB}, \mathrm{pH}$ 7.4, the sections were treated with $3 \% \mathrm{H}_{2} \mathrm{O}_{2}$ and $10 \%$ methanol for $15 \mathrm{~min}$ to eliminate endogenous peroxidase activity and were washed extensively with $0.1 \mathrm{M}$ Tris-buffered saline (TBS; pH 7.4). To block non-specific binding sites, the sections were then incubated with either $2 \%$ normal horse (for NP-NF, GAD, GlyR) or 2\% normal goat serum (for CR, UCN) in $0.3 \%$ Triton-X 100 in $0.1 \mathrm{M}$ TBS for $1 \mathrm{~h}$ at room temperature. Parallel $2 \mathrm{~mm}$ spaced series of neighboring sections were subsequently treated either with mouse 
anti-NP-NF (1:5000; Sternberger) or mouse anti-GAD (1:4000, Biotrend) or mouse anti-GlyR (1:300, Synaptic Systems) or rabbit anti-CR (1:2500, Swant) or rabbit anti-UCN (1:8000; Sigma) for 2 days at $4^{\circ} \mathrm{C}$. After washing in $0.1 \mathrm{M}$ TBS, the sections were incubated either in biotinylated horse anti-mouse $\operatorname{IgG}$ (1:200; Vector Laboratories) or biotinylated goat anti-rabbit IgG (1:200; Vector Laboratories) at room temperature for $1 \mathrm{~h}$, followed by three washes in $0.1 \mathrm{M}$ TBS. Then, sections were incubated in extravidinperoxidase (EAP; 1:1000; Sigma) for $1 \mathrm{~h}$ at room temperature. After two rinses in $0.1 \mathrm{M}$ TBS, and one rinse in $0.05 \mathrm{M}$ Tris-buffer (TB), $\mathrm{pH} 8$, the EAP complex indicating the antigenic sites was visualized by a reaction in $0.05 \%$ diaminobenzidine (DAB) and $0.01 \% \mathrm{H}_{2} \mathrm{O}_{2}$ in $0.05 \mathrm{M}$ TB for $10 \mathrm{~min}$. After several rinses in TBS, "free floating" sections were mounted, air-dried, dehydrated in increasing concentrations of alcohol and xylene, and coverslipped in DePex mounting medium (Serva, Heidelberg, Germany).

\section{Combined immunoperoxidase labeling for ChAT and GAD}

In selected paraffin sections, combined immunoperoxidase labeling was used to simultaneously detect ChAT and GAD.

After deparaffination and rehydration, the sections were washed in $0.1 \mathrm{M}$ TBS ( $\mathrm{pH} 7.4$ ), treated with $1 \% \mathrm{H}_{2} \mathrm{O}_{2}$ in TBS for $30 \mathrm{~min}$, were rinsed again, and preincubated with $2 \%$ normal rabbit serum in $0.3 \%$ Triton-X 100 in TBS for $1 \mathrm{~h}$ at room temperature. The sections were then treated with goat anti-ChAT (1:100; Chemicon, $\mathrm{AB} 144 \mathrm{P}$ ) in TBS with $2 \%$ rabbit serum and $0.3 \%$ Triton $\mathrm{X}-100$ for $48 \mathrm{~h}$ at room temperature. After three washes in $0.1 \mathrm{M}$ TBS, the sections were incubated in biotinylated rabbit anti-goat IgG (1:200, Vector Laboratories) in TBS containing $2 \%$ bovine serum albumin for $1 \mathrm{~h}$ at room temperature. After three washes in $0.1 \mathrm{M}$ TBS, the sections were treated with EAP (1:1000; Sigma) for $1 \mathrm{~h}$. Then, two rinses with $0.1 \mathrm{M}$ TBS were followed by one wash with $0.05 \mathrm{M} \mathrm{TB}, \mathrm{pH} 8$, and the reaction with $0.025 \% \mathrm{DAB}$, $0.4 \%$ ammonium nickel sulfate, and $0.015 \% \mathrm{H}_{2} \mathrm{O}_{2}$ in $0.05 \mathrm{M} \mathrm{TB}$, $\mathrm{pH}$, for $10 \mathrm{~min}$. This results in a black staining of ChAT-positive structures. After a thorough washing and blocking of residual peroxidase activity with $1 \% \mathrm{H}_{2} \mathrm{O}_{2}$ in $0.1 \mathrm{M}$ TBS, the sections were incubated in $2 \%$ normal horse serum in $0.3 \%$ Triton-X-100 in $0.1 \mathrm{M}$ TBS for $1 \mathrm{~h}$ at room temperature before being transferred to mouse anti-GAD (1:4000; Biotrend, GC 3108) in $2 \%$ normal horse serum and $0.3 \%$ Triton-X-100 in TBS for $24 \mathrm{~h}$ at room temperature. After washing in $0.1 \mathrm{M}$ TBS, the sections were incubated in biotinylated horse anti-mouse IgG (1:200; Vector Laboratories, Burlingame, CA, USA) in TBS containing 2\% bovine serum albumin for $1 \mathrm{~h}$ at room temperature. The antigen binding site was detected by incubating sections in EAP (1:1000; Sigma, St. Louis, MO, USA) for $1 \mathrm{~h}$ and a subsequent reaction with $0.025 \%$ DAB and $0.015 \% \mathrm{H}_{2} \mathrm{O}_{2}$ in $0.05 \mathrm{M} \mathrm{TB}$ ( $\mathrm{pH} 7.6$ ) for 10 min to yield a brown staining of $\mathrm{GAD}$-positive profiles. After washing, the sections were air-dried, dehydrated in alcohol, and coverslipped with DePex mounting medium (Sigma, St. Louis, MO, USA).

\section{ANALYSIS OF STAINED SECTIONS}

The slides were examined with a light microscope Leica DMRB (Bensheim, Germany). Brightfield photographs were taken with a digital camera (Pixera Pro 600 ES, Klughammer, Markt Indersdorf, Germany, or Microfire (Optronics, USA) mounted on the microscope. The images were captured on a computer with Pixera Viewfinder software (Klughammer, Markt Indersdorf) or Picture frame 2.2 (Optronics, USA) and processed with Photoshop 7.0 software (Adobe Systems, Mountain View, CA, USA). The sharpness, contrast, and brightness were adjusted to reflect the appearance of the labeling seen through the microscope. The pictures were arranged and labeled with drawing software (Coreldraw 11.0; COREL).

\section{QUANTIFICATION OF CR AND GAD INPUTS}

The CR and GAD inputs to all motoneuronal groups in nIII and nIV were quantified by counting immunoreactive puncta along the measured length of the contour of a motoneuron with Image J (public domain, Java-based image processing program developed at the National Institutes of Health). The values were transferred in a spreadsheet table for calculation of the statistics (Microsoft Excel, 2010). The analysis of each chosen group was performed on sections from two different cases. In one focus plane, the immunoreactive puncta along the outlines of at least 35 cells in each subgroup were counted. Simultaneous ChAT-immunolabeling was used to identify the motoneurons. Immunoreactive puncta were considered to contact a motoneuron, when its soma and the CR or GAD-positive terminal were in the same focal plane, and no space was seen between them. The ratio of the number of terminals per micrometer of cell outline was calculated with Excel software (Microsoft 2010). Then, the average and mean terminal density of inputs and the standard error of the mean were calculated for all motoneuronal subgroups, including those of the LP.

Data were analyzed with the PRISM 5 software (GraphPad Prism 5, San Diego, CA, USA). Statistical analysis was performed using a one-way analysis of variance (ANOVA). $p$ Values below 0.0001 were considered statistically significant. Two groups of downgaze motoneurons were identified: those that receive CR-input and those that do not. In addition, those groups of downgaze motoneurons receiving CR-input were separately analyzed and compared with the CR-input of upgaze motoneurons, using the Bonferroni's multiple comparison test. $p$ Values below 0.05 were considered statistically significant.

\section{RESULTS}

The cytoarchitecture of the nIV and nIII complex was visualized with Nissl- and Gallyas fiber staining, which revealed eight separate cell groups. All these cell groups differed in their staining pattern for the transmitter-related markers GAD, GlyR, and the calcium binding protein CR. These findings are described in detail in the following sections beginning with caudal levels.

\section{TROCHLEAR NUCLEUS}

With Nissl- and immunohistochemical staining for NP-NFs, the nIV can be delineated within the mesencephalic tegmentum. At the level of the inferior colliculus (IC), the nIV is clearly outlined as a round nucleus embedded in the fibers of the MLF (Figures 1A,B; corresponds to plate 32 in Olszewski and Baxter's work, 2nd edition, 1982, and 3rd edition by Büttner-Ennever and Horn, 2014). The NP-NF-staining reveals that the dendrites of the motoneurons are interwoven within nIV (Figure 1C with inset), and that they 

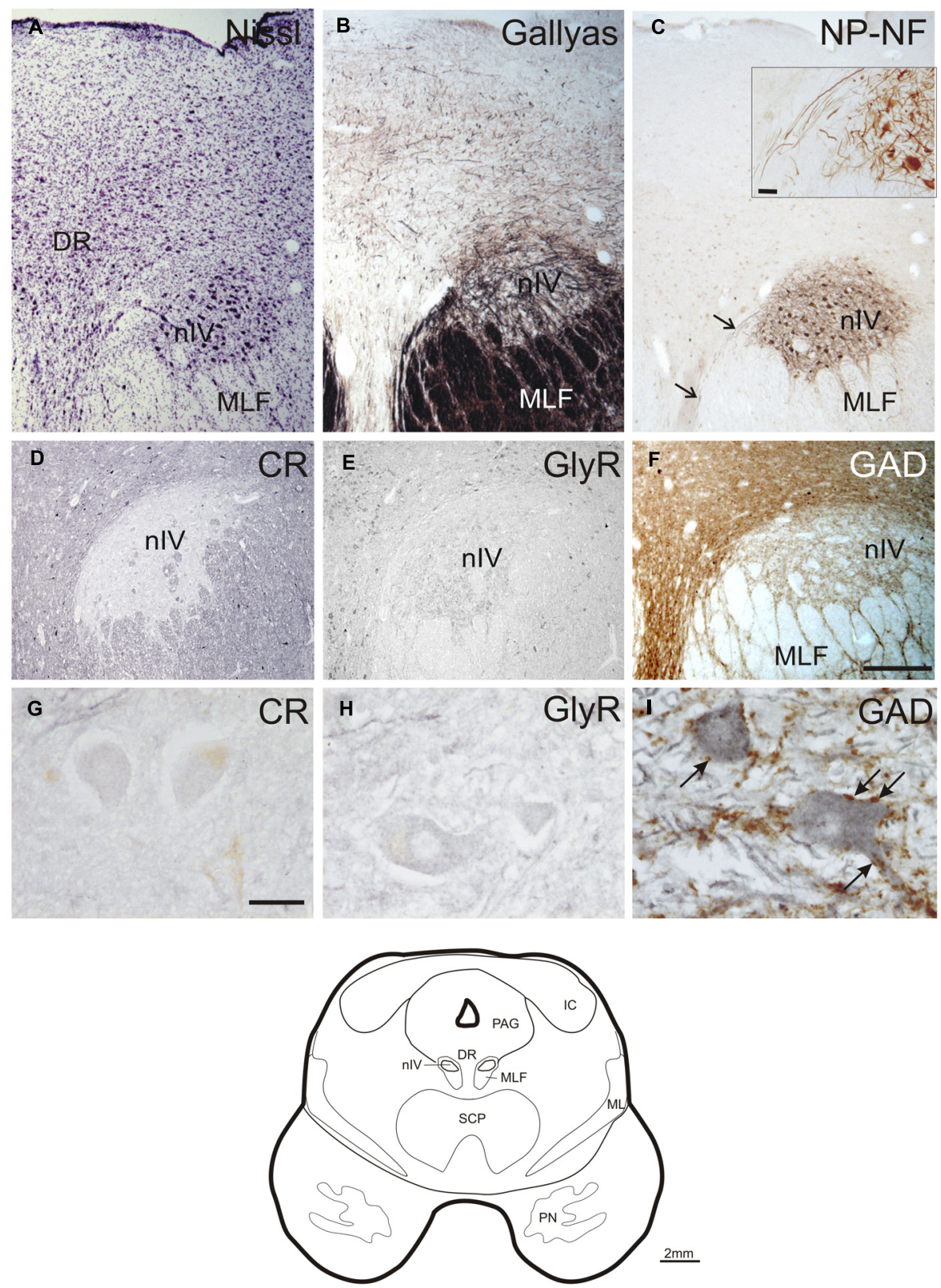

FIGURE 1 | Transverse sections of the human trochlear nucleus (nIV) demonstrating the cytoarchitecture in cresyl violet (A), Gallyas fiber staining (B), and immunostaining for non-phosphorylated neurofilaments (NP-NF) (C). The nIV is devoid of calretinin (CR) expressing neurons and fiber profiles $(\mathbf{D}, \mathbf{G})$, and it does not express immunoreactivity for the glycine receptor (GlyR) (E,H). The nIV shows a modest supply by GABAergic punctate profiles revealed with antibodies against glutamate decarboxylase (GAD) (F). Panels (A-C, F) show neighboring $40 \mu \mathrm{m}$ frozen sections of one case, panels (D,E) show neighboring $10 \mu \mathrm{m}$ paraffin sections of another case. Panels (G-I) are detailed views from (D-F). A line drawing the midbrain section at this level is given at the bottom. DR, dorsal raphe nucleus; IC, inferior colliculus; $M L$, medial lemniscus; MLF, medial longitudinal fascicle; PAG, periaqueductal gray; PN, pontine nuclei; SCP, superior cerebellar peduncle. Scale bar: (A-F) $500 \mu \mathrm{m} ;(\mathbf{G}-\mathbf{I}, \mathbf{C})$ inset $30 \mu \mathrm{m}$. are confined to the nucleus at the medial and dorsal aspects. The dendrites extend from the nuclear boundaries at the lateral and ventral aspects and intermingle between the fibers of the MLF. The axons travel medial to the MLF (Figure 1C, arrows, inset). As reported by others, two completely separate divisions of the nIV are apparent in the caudo-rostral direction (not shown; Pearson, 1943; Büttner-Ennever and Horn, 2014).
No CR-positive neurons or puncta were found within the boundaries of nIV (Figures 1D,G). The same observation was made for GlyR-immunostaining (Figures 1E,H). GADimmunostaining did not reveal any labeled somata within nIV, but numerous labeled puncta were detected around cholinergic motoneurons, many of them most likely representing synaptic terminals (Figures 1F,I, arrows). 


\section{CENTRAL CAUDAL NUCLEUS AND CAUDAL OCULOMOTOR NUCLEUS}

The caudal end of nIII appears as a V-shaped nucleus with the CCN dorsally embedded in the V-opening shown on a plane approximately $2 \mathrm{~mm}$ further rostral to nIV (Figures 2A-C; corresponds to plate 34 in Büttner-Ennever and Horn, 2014). At this plane, a small group of densely packed neurons adjacent to the dorsal rim of nIII becomes apparent in Nissl-stained sections. This cell group consists of UCN-positive neurons (Ryabinin et al., 2005; Horn etal., 2008) and has recently been termed EWcp (Figure 2A; Kozicz et al., 2011). As shown earlier, the EWcp does not express NP-NF-immunoreactivity (Figure 2C, arrow; Horn et al., 2008). Within the main nIII, four subgroups can be delineated at this level: a ventral (VEN) group outlined dorsomedially by traversing fibers shown by Gallyas fiber staining (Figure 2B), and a central (CEN) group dorsal to it (Figures 2A,C). A lateral (LAT) group is apparent as cell islands between the rootlets of the third nerve (NIII), separated from the main nucleus by the traversing fibers of the MLF (Figures 2A-C). A dorsolateral group (DL) appears as a relatively isolated circular subnucleus, most apparent in Gallyas staining and NP-NF-immunostaining (Figures 2B,C).

A strong supply by CR-positive fibers and nerve endings was evident in the CEN group, thereby highlighting it selectively from CR-negative DL and DM groups (Figures 2D and 3D; Figures 4A,D). A considerable supply was also found around the LP motoneurons in the CCN (Figures 2D,G). Immunostaining for the GlyR revealed a strong signal in the CCN (Figure 2E). At high magnification, the GlyR-immunostaining appears as diffuse staining of the neuronal somata and punctate labeling along the neuronal membrane surface of somata and dendrites of LP motoneurons (Figure 2H). Within the nIII, the DL and VEN subgroups were highlighted by their strong GlyR-immunostaining (Figure 2E). As in nIV, a strong supply by GAD-immunopositive puncta was evident in CCN and in all subgroups of the caudal nIII (Figures 2F,I). The DL and VEN subgroups were outlined by their relatively stronger abundance of GAD-positive punctate labeling compared to other subgroups (Figure 2F).

\section{MID nIII, NUCLEUS OF PERLIA}

At planes through the nIII $2 \mathrm{~mm}$ further rostral (corresponding to plate 36, Büttner-Ennever and Horn, 2014), the medial portion of the EWcp appears between the dorsal parts of nIII (Figures 3A-F). The NP-NF-negative EWcp is embedded in dorsoventrally traveling fibers (Figures 3B,C). At the midline of this level, an unpaired cell group is separated from the main nIII by dorsoventrally traversing fibers. This nucleus is called the nucleus of Perlia (NP) (Figures 3A-C; Perlia, 1889). Between EWcp and the DL group, an additional dorsomedial group (DM) appears at this level (Figures 3A-F).

Calretinin-immunostaining revealed only a few scattered small CR-positive neurons in nIII, mainly at the dorsomedial and medial border between both nIII. A group of CR-positive neurons is present in the dorsal, medial, and ventral perioculomotor region, in part covering the EWcp (Figures 3D and 4M). The careful analysis of neighboring $5 \mu \mathrm{m}$ thick paraffin sections, stained either for CR or UCN (Figures 3G-I), revealed that both populations do not overlap to any great extent. Only few UCN-positive neurons in EWcp express CR-immunoreactivity (Figures 3H,I, arrows). The CR-positive neurons in EWcp may form the origin of at least one portion of the dorsoventrally running fibers that embrace the NP and separate it from the lateral nIII (Figure 3D, arrows, insert). As for CCN and CEN, a considerable supply of CR-positive axonal profiles was found around neurons in NP (Figures 3D and $4 G, J)$.

Whereas CEN, NP, and EWcp were largely devoid of GlyRpositive neuronal profiles (Figures $3 \mathbf{E}$ and $\mathbf{4 H}, \mathbf{K}, \mathbf{N}$ ), the DM expressed some GlyR-immunoreactivity in addition to DL and VEN (Figures 3E and 4B,E). The GlyR-labeling of DM most probably represents dendrites of the adjacent motoneurons of LP and the DL group, which are strongly labeled (Figures 4B,E). The close inspection of sections stained for ChAT and GAD revealed that in all nIII subgroups the somata and proximal dendrites of the cholinergic motoneurons were associated with GAD-immunoreactive profiles. A similar strong GAD-input was found in the DL, CEN, VEN subgroups, as in the NP (Figures 4C,I,L). The DM, LAT showed the weakest supply from GAD-positive puncta, the non-cholinergic neurons in EWcp the strongest (Figures 4F,O).

\section{ROSTRAL nIII}

Another $2 \mathrm{~mm}$ further forward, at the rostral end of nIII, the DL is the only remaining subgroup. It is bordered by the EWcp, which forms a large cell group dorsally and a small extension ventrally (Figure 5A; corresponding to plate 38, Büttner-Ennever and Horn, 2014). Interestingly at this level fibers arising from the nIII of both sides intermingle intensely with each other, apparent from Gallyas staining and NP-NF-immunostaining (Figures 5B,C,E,F, arrows). GAD-positive puncta covered the DL and EWcp densely (Figure 5D).

\section{QUANTITATIVE ANALYSIS OF GAD AND CR-POSITIVE INPUTS}

A summarized view of the histochemical properties is given in Figure 6. For verification of the impression received from visual inspection, the GAD- and CR-positive inputs were quantified by counting immunoreactive puncta along the outlines of the perimeter of somata and proximal dendrites in all subgroups of nIII and nIV. The quantitative analysis of GAD-positive puncta confirmed the visual impression, and revealed that the strongest GABAergic input was found to the somata of EWcp neurons (Figures 6C,E,G,I,K and 7A; see also Figure 4O) with an averaged density of 0.183 puncta/ $\mu \mathrm{m}$ (see Table 3 ). Similar strong GADinput was found to the motoneurons in nIV, CEN, DL, VEN, NP, and CCN (Table 3; Figures 6A,C,E,G,I,K and 7A). The weakest supply was found to involve motoneurons in the DM and LAT subgroups (Table 3; Figures 6A,C,E,G,I,K and 7A). The one-way ANOVA revealed a significant difference of the mean values with $p<0.001$ (Figure 7A). GlyR-immunostaining was only found in CCN and the DL and VEN subgroups in nIII, all with a similar intensity (Figures 6C,E,G,I,K). All motoneurons including neurons of NP expressed ChAT- and NP-NF-immunostaining, the neurons in EWcp contain UCN, as already shown previously (Horn et al., 2008; Figures 6B,D,F,H,J,L).

As is apparent from visual inspection of the immunocytochemical staining, the strongest CR-input is found around neurons of the NP, and around motoneurons in CEN (Table 3; 

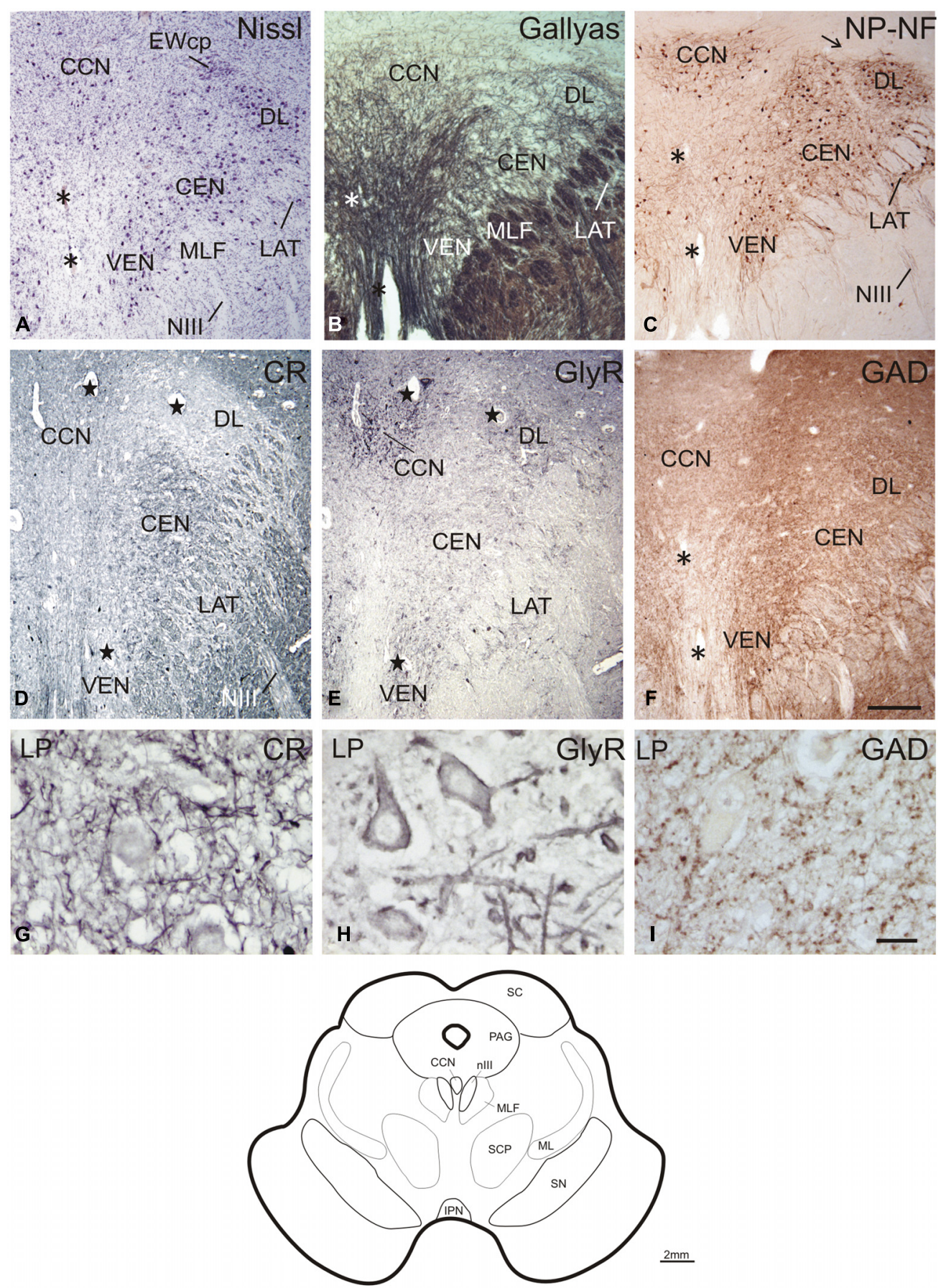

FIGURE 2 | Transverse sections through the caudal plane of the oculomotor nucleus (nIII). Cresyl violet (A), Gallyas fiber staining (B), and immunostaining for non-phosphorylated neurofilaments (NP-NF) (C) reveal several subnuclei of the oculomotor nucleus complex that exhibit different staining patterns for calretinin (CR) (D), glycine receptor (GlyR) (E), and glutamate decarboxylase (GAD) (F). The central caudal nucleus (CCN) appears as a separate nucleus embedded in the medially descending fibers (A-C). The CCN is high-lighted by its GlyR expression (E) and shows a moderate supply by CR- and GAD-positive profiles (D,F). A dorsolateral group (DL) of nlll is separated by encircling fibers (A-C). DL is devoid of CR-positive profiles (D), but rich in GlyR-and GAD-positive profiles (E,F). A similar pattern is seen for the ventral group (VEN) and lateral group (LAT), which forms an island of cells within the medial longitudinal fascicle (MLF)
(A-F). A central group (CEN) is high-lighted by its strong expression of CR (D), but shows less staining for GAD (F) and almost none for GlyR (E) Panels (A-C,F) show neighboring $40 \mu \mathrm{m}$ frozen sections of one case, (D,E) neighboring $10 \mu \mathrm{m}$ paraffin sections of another case. Panels $(\mathbf{G}-\mathbf{I})$ are detailed views from (D-F). Asterisks label corresponding blood vessels in neighboring frozen sections of one case $\mathbf{( A - C , F )}$, stars label those in neighboring paraffin sections from a different case (D,E). Detailed views of levator palpebrae (LP) motoneurons in CCN are shown for CR (G), GlyR (H), and GAD-immunoreactivity (I). A line drawing at the bottom shows the midbrain section at this level. IPN, interpeduncular nucleus; $\mathrm{ML}$, medial lemniscus; PAG, periaqueductal gray; SC, superior colliculus; SCP, superior cerebellar peduncle; scale bars: (A-F) $500 \mu \mathrm{m}$;

(G-I) $30 \mu \mathrm{m}$. 

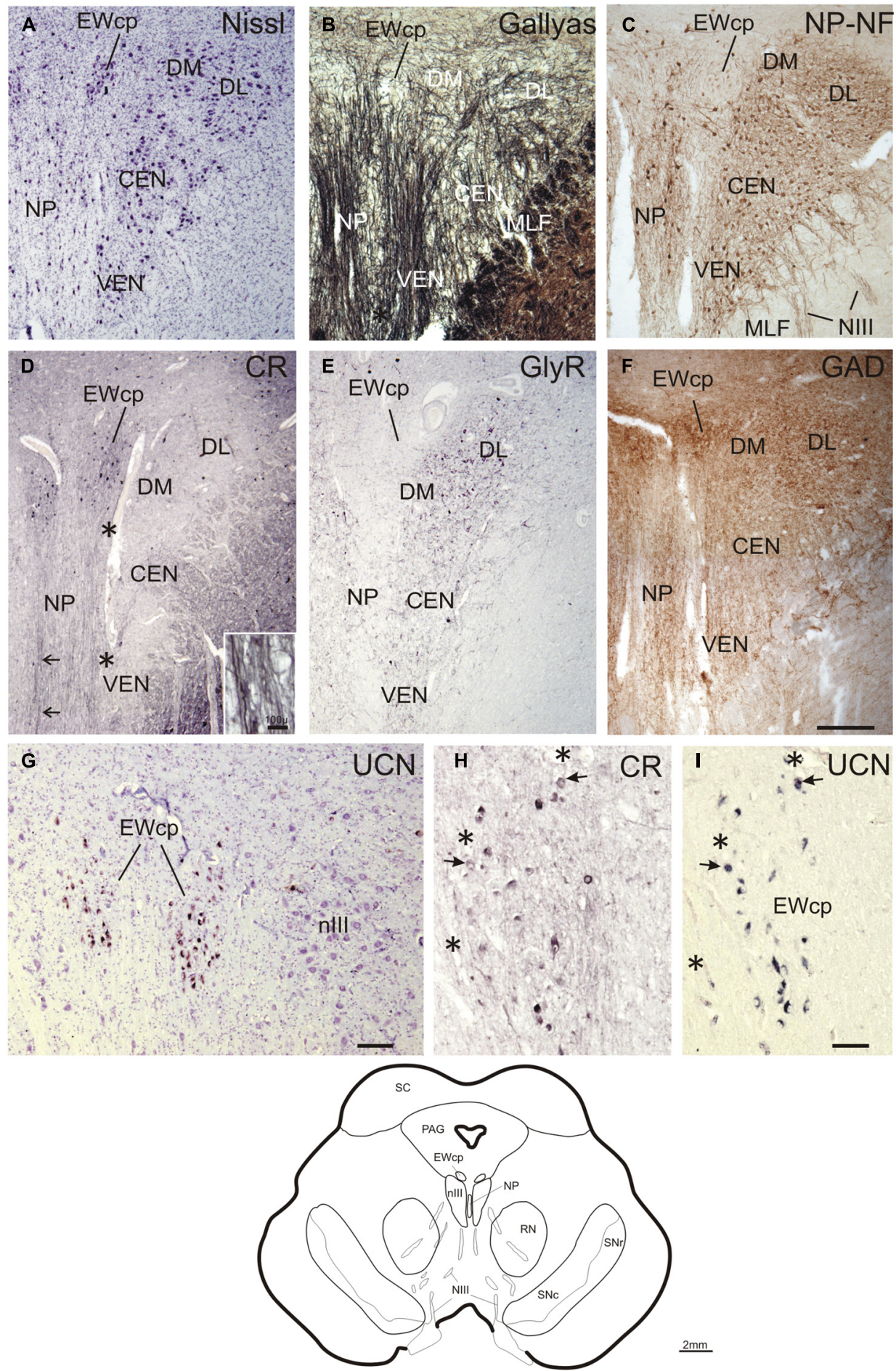

FIGURE 3 | Transverse sections at the level of the mid oculomoto nucleus (line drawing at the bottom). Cresyl violet (A), fiber staining (B), and immunostaining for non-phosphorylated neurofilaments (NP-NF) (C) reveal six subnuclei of the nlll complex at this level that exhibit different staining patterns for calretinin (CR) (D), glycine receptor (GlyR) (E), and glutamate decarboxylase (GAD) (F). The nucleus of Perlia (NP) forms an elongated midline cell group separated from the main nucleus by dorsoventrally traversing fibers (A,B), some expressing CR-immunoreactivity (D, arrows, inset). At the dorsomedial border of nIII, a compact cell group forms the centrally projecting non-preganglionic part of the Edinger-Westphal nucleus (EWcp), which contain urocortin (UCN)-positive and some scattered CR-positive neurons (D,G). The EWcp does not contain NP-NF (C), is devoid of GlyR (E), but receives a strong GAD input (F). High power magnification of two adjacent $5 \mu \mathrm{m}$ paraffin sections immunostained for $\mathrm{CR}$ and UCN reveal only few UCN-positive neurons expressing CR (H,I, arrows). Corresponding blood vessels are indicated by asterisks. PAG, periaqueductal gray; $R N$, red nucleus; SC, superior colliculus; SN, substantia nigra (reticulata and compacta). Scale bar: (A-F) $500 \mu \mathrm{m}$; (G) $100 \mu \mathrm{m}$; (H,I) $50 \mu \mathrm{m}$ 


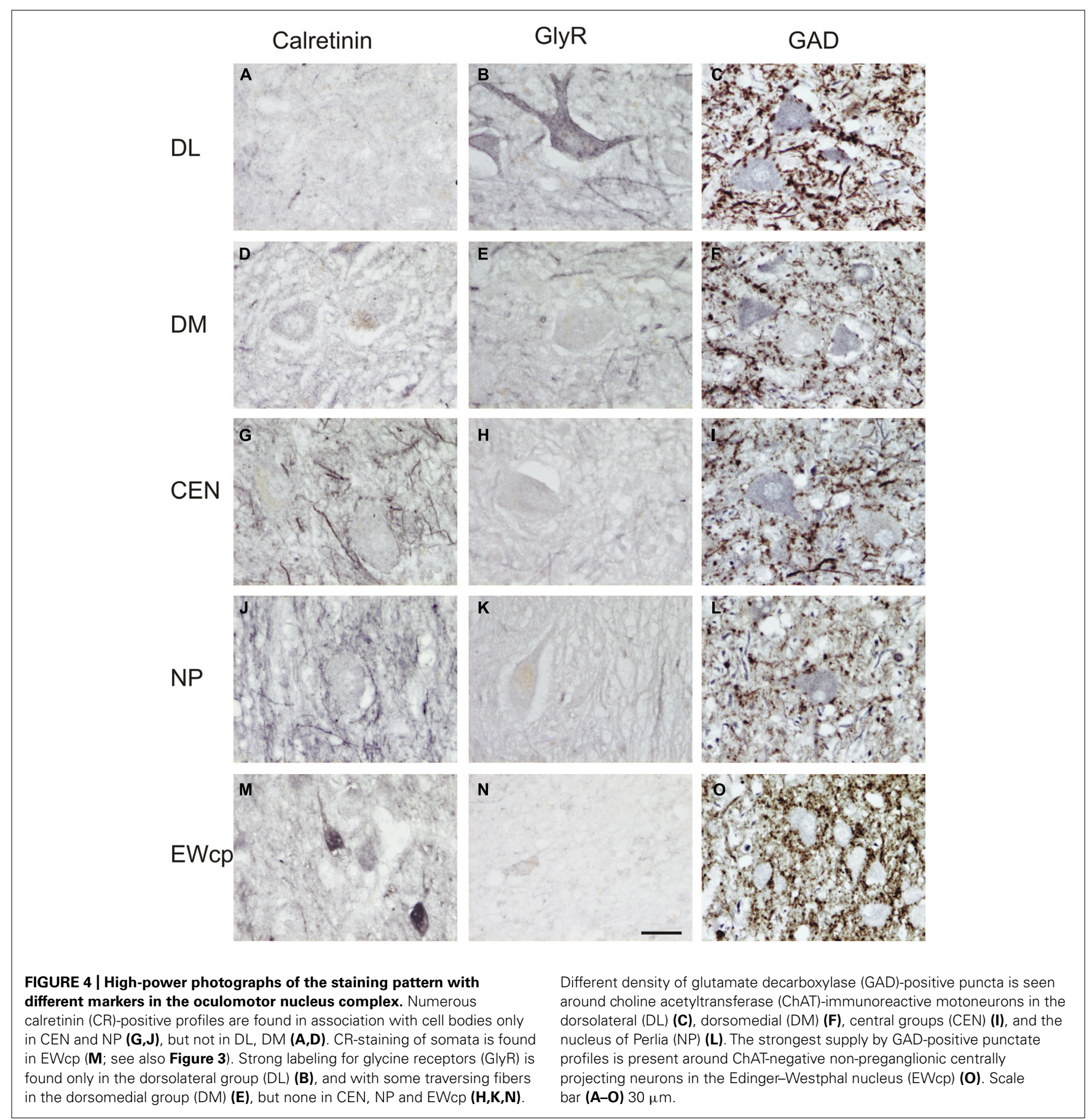

Figures 6D,F,H,J and 7B). Furthermore, a high density of CRpositive puncta was noticed in the $\mathrm{CCN}$ with 0.051 puncta/ $\mu \mathrm{m}$ (Table 3; Figures 6D and 7B). In contrast, only a few motoneurons in all other motoneuronal subgroups were associated with CR-positive profiles at an average density of around 0.01 puncta/ $\mu \mathrm{m}$ (Table 3 ; Figure 7B). A comparative analysis revealed that the density of CR-positive puncta around motoneurons for upgaze in CCN and the CEN subgroup was significantly stronger than those around motoneurons for downor horizontal gaze $(p<0.001)$. Even those down- and horizontal gaze motoneurons receiving some CR-input were contacted by significantly less CR-positive puncta, when separately analyzed and compared with the CR-input of upgaze motoneurons (Bonferroni's multiple comparison test; $p<0.05$; not shown).

\section{DISCUSSION}

In this study of the histochemical characteristics of the human nIII and nIV, eight cell groups were distinguished from each other. From these results, and those of a previous study on non-human primates (Zeeh et al., 2013), a map of the subgroups of the human 

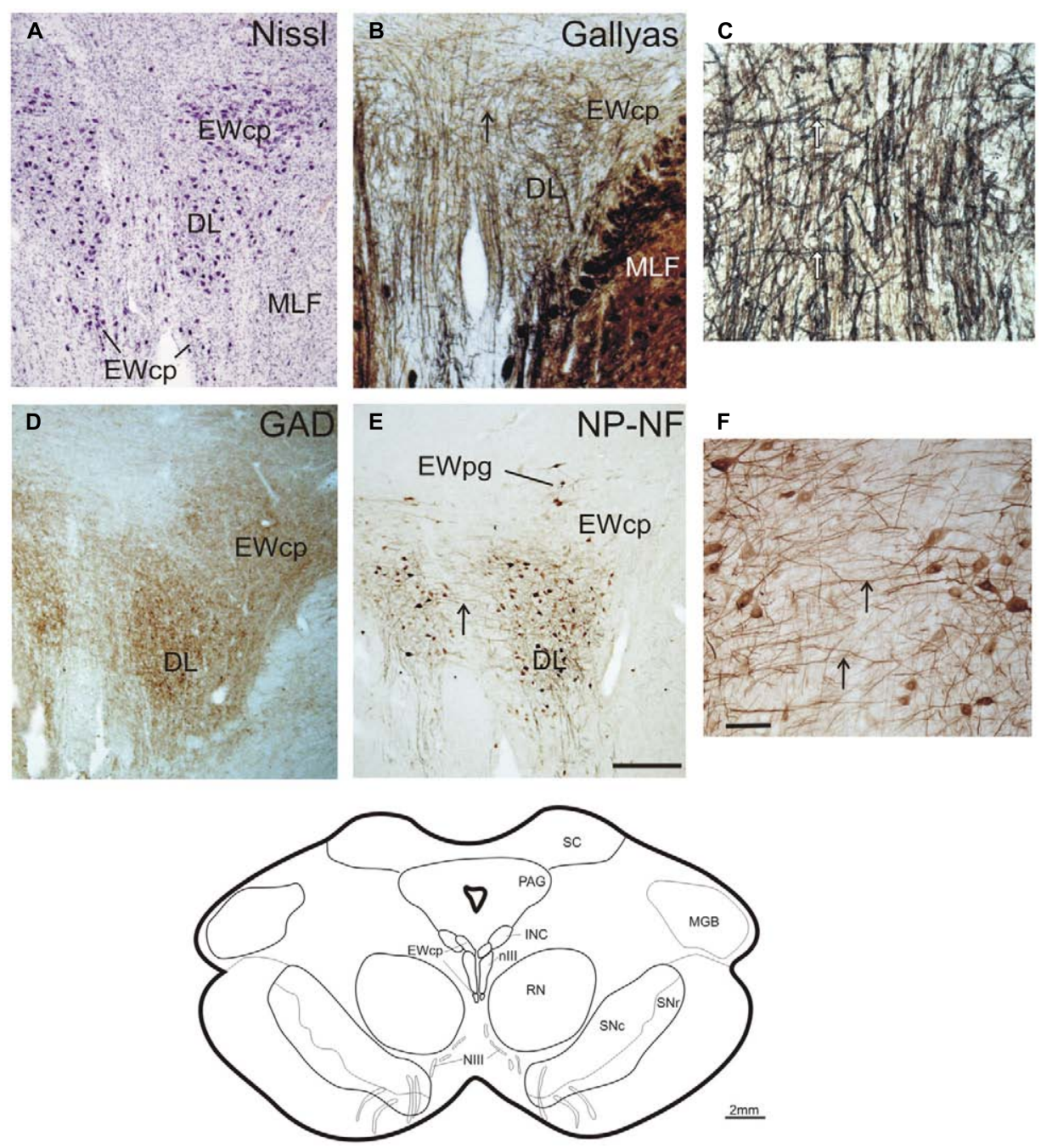

FIGURE 5 | Transverse sections at the level of the rostral oculomotor nucleus (line drawing at the bottom). Cresyl violet (A), Gallyas-fiber staining (B) with detail (C), immunostaining for glutamate decarboxylase (GAD) (D), and non-phosphorylated neurofilaments (NP-NF) (E) with detail (F). Note, unlike the preganglionic neurons of the Edinger-Westphal nucleus (EWpg), the centrally projecting non-preganglionic neurons of EWcp do not express non-phosphorylated neurofilaments (NP-NF) (C). The strong labeling of GAD-positive puncta in the most rostral group in the nlll speaks for a continuation of the dorsolateral group (DL), which most likely corresponds to the medial rectus B-group in monkey (D). Note the presence of numerous crossing fibers between both nlll at this level (B,C,E,F, arrows). INC, interstitial nucleus of Cajal; MGB, medial geniculate body; PAG, periaqueductal gray; $R N$, red nucleus; $S N$, substantia nigra (reticulata and compacta). Scale bar: (A,B,D,E) $500 \mu \mathrm{m}$; (C,F) $100 \mu \mathrm{m}$.
nIII is drawn up here, proposing the target of innervation, for each individual subgroup. In the following sections, the subgroups will be discussed in terms of their proposed function.

\section{OCULOMOTOR SUBGROUPS INVOLVED IN UPGAZE}

\section{Motoneurons of superior rectus and inferior oblique muscles}

As in monkey, only selected subgroups within nIII receive a strong input from CR-positive afferents (Zeeh et al., 2013); in human these include the CCN, the CEN group, and NP. Combined tract-tracing and CR-immunostaining experiments in monkey have shown that the CR-positive input was confined to motoneurons participating in upgaze, e.g., SR, IO, and LP in the CCN (Fuchs et al., 1992; Zeeh et al., 2013). Furthermore, tracer injections into the IO or SR muscles in monkey revealed that these two subgroups occupy a similar portion in the central part of the caudal nIII, except for the fact that the SR motoneurons are located contralaterally and tend to lie more medially to the IO motoneurons, which project to the ipsilateral eye muscle. The dendrites of retrogradely labeled IO and SR motoneurons are intimately intermingled and are not confined to any individual cytoarchitectural borders (Spencer and Porter, 1981; Zeeh etal., 2013). Based on the similar anatomical and histochemical features of the CEN group including the selective CR input, the CEN subgroup in the human nIII is considered as the location of SR and IO motoneurons (Figure 8).

With combined tract-tracing studies, three sources of the $\mathrm{CR}$ input to the nIII complex have been identified in monkey: 


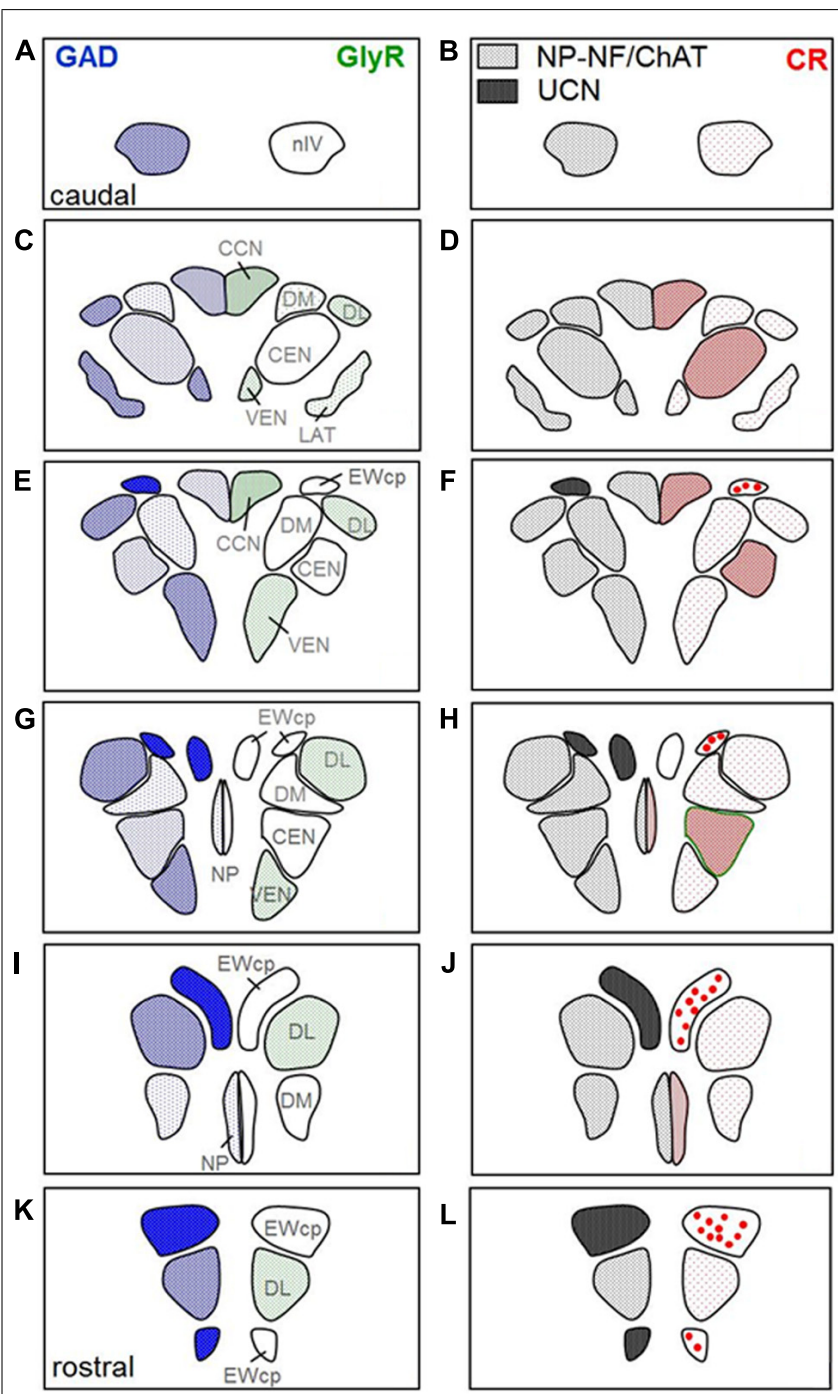

FIGURE 6 | Two parallel series of drawings of transversal sections through the trochlear (nIV) and oculomotor nucleus (nIII) complex arranged from caudal to rostral. Panels $(\mathbf{A}, \mathbf{B})$ correspond to the level of Figure 1, (C,D) to the level of Figure 2, $(\mathbf{G}, \mathbf{H})$ to the level of Figure 3, and $(\mathbf{K}, \mathbf{L})$ to the level of Figure 5. Panels $(\mathbf{E}, \mathbf{F}$ and $\mathbf{I}, \mathbf{J})$ correspond to additional intermediate levels. On the left, the density of glutamate decarboxylase (GAD) positive puncta and the intensity of immunostaining for the glycine receptor (GlyR) in the different subgroups is indicated by blue hatching on the left and green hatching on the right, respectively. The right column shows the presence of neurons expressing immunoreactivity for urocortin (UCN, black), non-phosphorylated neurofilaments (NP-NF; gray) and calretinin (CR; red filled circles). The density of CR-positive profiles is indicated by different grades of red hatching.

the rostral interstitial nucleus of the medial longitudinal fascicle (RIMLF), the interstitial nucleus of Cajal (INC) and the $y$ group of the vestibular nuclei (Ahlfeld et al., 2011). The RIMLF contains premotor neurons of different types; some exhibit a highfrequency burst for upward saccades, others for downward saccades, and they are all intermingled with each other (Büttner et al., 1977; Horn and Büttner-Ennever, 1998). Considering their targets, the CR-positive population probably represents the premotor

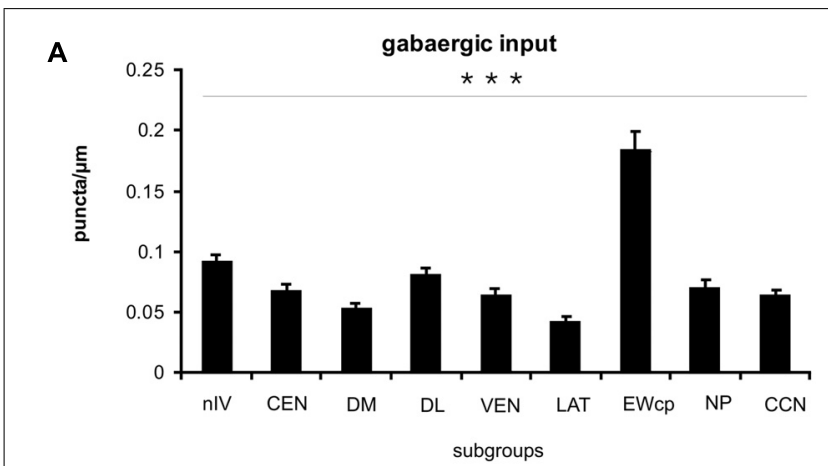

B

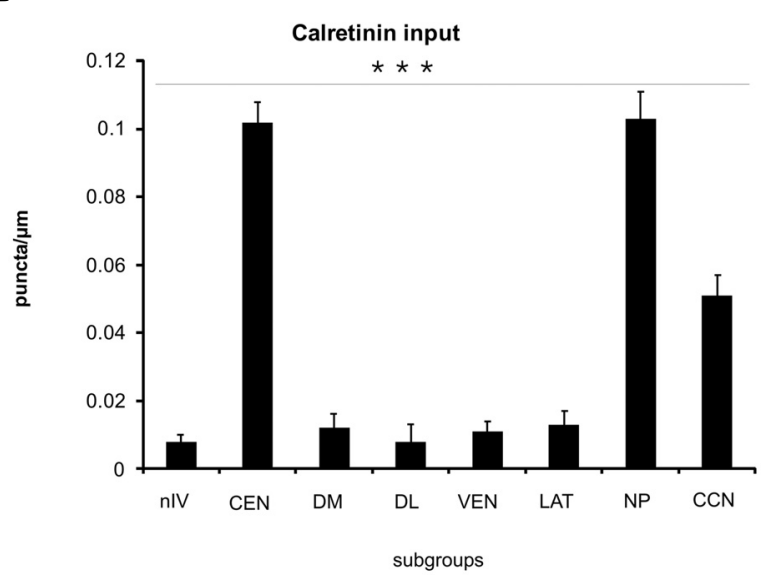

FIGURE 7 | Histogram of the quantitative analysis of GABAergic and calretinin (CR) input to motoneurons in the oculomotor and trochlear nucleus. The values are given in Table 3. (A) The GABA-input was quantified by counting glutamate decarboxylase-positive (GAD) puncta along the measured length of the contour of a given neuron. The mean terminal density of input and the standard error of the mean values were calculated for each subgroup. The one-way analysis of variance revealed a significant difference $(p<0.001)$. The strongest input is seen to non-preganglionic centrally projecting neurons in the Edinger-Westphal nucleus (EWcp; compare to Figure 40), whereas the neurons of all other subgroups did not show major differences. (B) The strongest CR input is seen to neurons of the nucleus of Perlia (NP), the central group in oculomotor nucleus (CEN), and the central caudal nucleus (CCN). The number of counted CR-positive puncta associated with putative upgaze motoneurons is significantly higher compared to those around horizontal - and downgaze motoneurons $\left(^{* *} p<0.001\right.$ ).

burst neurons for upward saccades (Ahlfeld et al., 2011). The CR-input from INC to upgaze motoneurons may derive from premotor burst-tonic neurons involved in integration of the velocity signal from RIMLF into the eye-position signal, required for gaze stabilization after a saccade (Fukushima et al., 1992). The lack of GAD in CR-immunopositive neuronal profiles in monkey nIII as revealed by double-immunofluorescence and confocal scanning, indicated that the CR input is excitatory (Zeeh et al., 2013). CRpositive projections from the y-group to SR and IO motoneurons may provide the excitatory drive during smooth pursuit eye movements (Partsalis et al., 1995). The functional significance of the selective CR presence in upgaze pathways remains unclear, it has been discussed in previous publications (Ahlfeld et al., 2011; Zeeh et al., 2013). 
Table 3 | Quantification of calretinin and GABAergic input to nIV and nIll subgroups.

\begin{tabular}{llllll}
\hline & \multicolumn{3}{c}{ CR } & & \multicolumn{2}{c}{ GAD } \\
\cline { 2 - 3 } \cline { 5 - 6 } Subgroup & Puncta/ $\boldsymbol{\mu} \mathbf{m}$ & SE of mean & & Puncta/ $\mathbf{\mu m}$ & SE of mean \\
\hline nIV & 0.008 & 0.002 & & 0.091 & 0.006 \\
CEN & 0.102 & 0.006 & & 0.067 & 0.006 \\
DM & 0.012 & 0.004 & & 0.052 & 0.005 \\
DL & 0.008 & 0.005 & & 0.08 & 0.006 \\
VEN & 0.011 & 0.003 & & 0.063 & 0.006 \\
LAT & 0.013 & 0.004 & & 0.041 & 0.005 \\
NP & 0.103 & 0.008 & & 0.069 & 0.008 \\
CCN & 0.051 & 0.006 & 0.063 & 0.005 \\
EWcP & 0 & 0 & 0.183 & 0.016 \\
\hline
\end{tabular}

\section{Central caudal nucleus}

Panegrossi (1898), was the first to describe the CCN in human. Originally he had termed the nucleus on the midline, situated between the oculomotor nuclei at caudal levels, as nucleus posterior dorso-centralis. He found this nucleus as a constant feature in human, and noted it also in monkey, dog, and cat. Since this nucleus degenerated after removal of the bulbus in cat, he designated it as part of the nIII (review: Warwick, 1953a,b). Similarly, Tsuchida (1906) described a central medial nucleus between the main cell columns of caudal nIII, but he did not relate it to Panegrossi's findings. He called this medial nucleus the caudal central nucleus (Tsuchida, 1906). In spite of the fact that Tsuchida (1906) designated it probably to the dorsal raphe nucleus, his term was later adopted for the midline nucleus containing LP motoneurons. Based on removal of individual eye muscles in monkey, Warwick was the first to show that the CCN contains the LP motoneurons (Warwick, 1953b). This was later confirmed with tract-tracing methods, also showing that the LP motoneurons of both eyes are intermingled within the CCN, with a slight predominance for a contralateral representation (Porter et al., 1989). There are conflicting reports as to whether some LP motoneurons innervate the muscles of both sides (Sekiya et al., 1992; Van der Werf et al., 1997), or whether LP populations are completely separated for each eye (Porter et al., 1989). As in monkey, the CCN in human forms an unpaired nucleus dorsal to the caudal end of nIII (Schmidtke and Büttner-Ennever, 1992; Horn and Adamcyzk, 2011; Büttner-Ennever and Horn, 2014). Furthermore, the present study revealed, that in addition to a significant CR-input, there is a strong input from GABAergic and glycinergic afferents to LP motoneurons, as found in monkey (Horn and Büttner-Ennever, 2008; Zeeh et al., 2013). One possible source of direct or indirect inhibitory GABAergic afferents is the nucleus of the posterior commissure, since lesions of this area result in lid retraction (Schmidtke and Büttner-Ennever, 1992; Averbuch-Heller, 1997). A further direct inhibitory connection was shown from pontine neurons at the rostral and ventral border of the principal trigeminal nucleus to LP motoneurons in the CCN, which presumably provide the inhibition during blinks
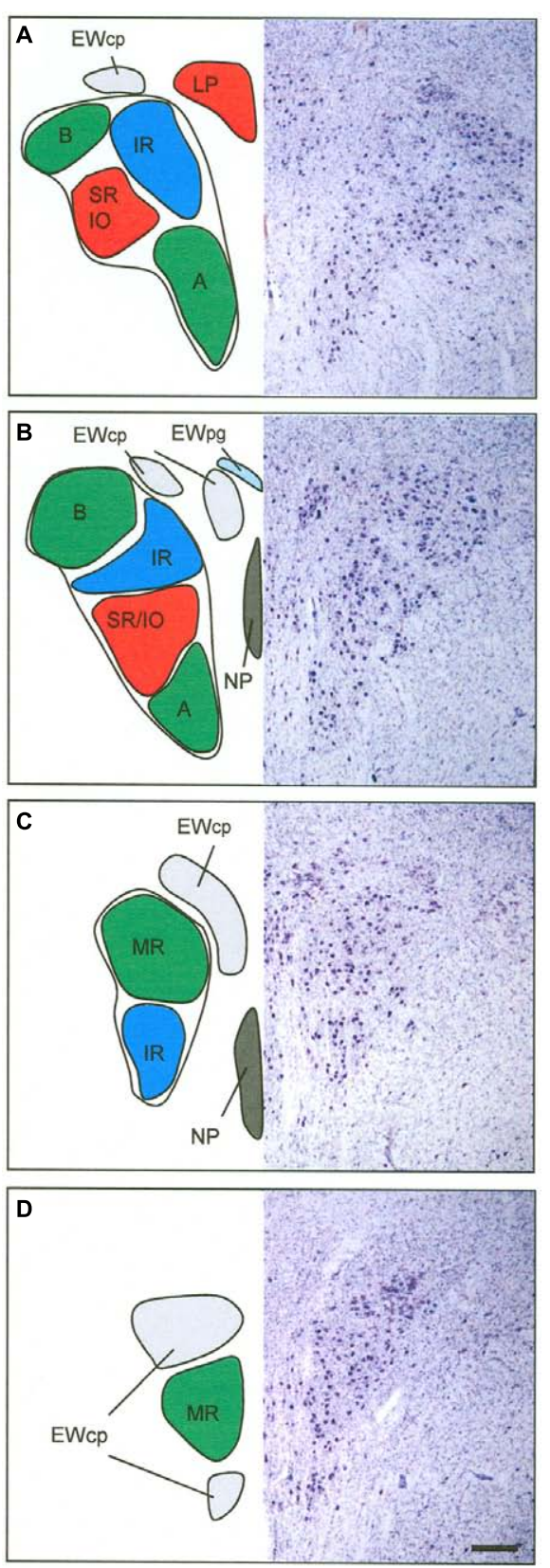

FIGURE 8 | Proposed map of the motoneurons for individual extraocular muscles in human shown at four representative planes from caudal to rostral. The right half shows corresponding sections in Nissl staining to demonstrate the cytoarchitecture. The central caudal nucleus at most caudal planes contains the motoneurons of the levator palpebrae muscle (LP) (A). The medial rectus muscles (MR) is represented in two groups, the dorsolateral B-and the ventral A-group (A,B). The central group represents the motoneurons of the inferior oblique $(\mathrm{IO})$ and superior rectus (SR) muscle $(\mathbf{A}, \mathbf{B})$. The nucleus of Perlia (NP) is separated from the main nucleus, but may contain SR motoneurons as well (B,C). The dorsomedial group corresponds to the inferior rectus motoneurons (IR) (A-C). The centrally projecting neurons of the Edinger-Westphal nucleus (EWcp) appear as a single lateral group on caudal levels dorsal to nIII (A), adjoined by a medial group further rostrally $(\mathbf{B})$, which both merge to a single dorsal group (C). Another ventral extension of the EWcp appears on rostral levels (D). Note that the preganglionic neurons in the EWpg do not form a compact nucleus (B). Scale bar: (A-D) $500 \mu \mathrm{m}$. 
(May et al., 2012). The glycinergic input to LP motoneurons may originate from saccadic omnipause neurons, as indicated by tracttracing studies in monkey (Horn and Büttner-Ennever, 2008). The function of this connection is not clear, yet, but may contribute to pathways involved in blink-saccade interaction (Leigh and Zee, 2006).

Premotor neurons in the medial RIMLF in cat, and in the M-group in monkey, which target LP motoneurons, represent a further possible CR source (Horn et al., 2000; Chen and May, 2002). Furthermore, a monosynaptic excitatory connection from INC to LP motoneurons has been described in cat (Chen and May, 2007). This projection may originate from the same premotor neurons in INC, which target SR and IO motoneurons, thereby coupling vertical eye and lid movements not only during saccades, but also during gaze holding, to provide a larger, and freer upper field of vision.

\section{Nucleus of Perlia}

The NP was described by Perlia (1889) and originally considered as a cell group participating in the control of convergence, but up to now, without any proof (Warwick, 1955). In spite of several references describing the presence of the NP in non-human primates as a labeled midline group, after tracer injections into the ciliary ganglion (Burde, 1983, 1988; Burde and Williams, 1989; Ishikawa etal., 1990), its existence is still questioned in these species. The tracer labeled neurons are more likely to represent motoneurons of multiply-innervated muscles fibers (MIF) of the IO and SR, due to superficial contamination of the muscles as discussed previously (Büttner-Ennever et al., 2001; Horn et al., 2008). In fact, the morphology of the neurons of NP and their histochemical properties, e.g., expression of ChAT, cytochrome oxidase, NP-NF, and chondroitin sulfate proteoglycans, suggest that they may present motoneurons of singly-innervated twitch muscle fibers (SIF; Eberhorn et al., 2005; Horn et al., 2008). The present study demonstrated a CR input to NP and thereby indicates a role in upgaze, which supports the hypothesis that NP may represent SR twitch motoneurons that are separated from the main subgroup in nIII by dorsoventrally traveling nerve fibers (Horn et al., 2008; Büttner-Ennever and Horn, 2014).

\section{OCULOMOTOR SUPGROUPS INVOLVED IN DOWNGAZE Motoneurons of superior oblique and inferior rectus muscles}

In addition to the SO motoneurons in $\mathrm{nIV}$, the IR motoneurons in nIII participate in downward eye movements (Leigh and Zee, 2006). In monkey, the IR motoneurons lie within the rostral half of nIII appearing medial to the B group of the MR motoneurons. At the rostral end of nIII they form the dorsal part of nIII (Evinger, 1988; Büttner-Ennever, 2006). Unlike motoneurons of horizontal moving eye muscles, a strong GABAergic input was found to the motoneurons of all vertically pulling eye muscles in monkey, including those for downgaze (Spencer and Baker, 1992). One well known source for GABAergic afferents to the vertically pulling eye muscles arises from the secondary vestibulo-ocular neurons in the superior vestibular nuclei (de la Cruz et al., 1992; Wentzel et al., 1996; Highstein and Holstein, 2006). Electrophysiological and pharmacological studies have shown that stimulation of the vestibular nerve results in inhibitory postsynaptic potentials in the ipsilateral nIV and nIII, which are blocked after administration of GABA antagonists (Obata and Highstein, 1970). Similarly, a lesion of the MLF results in a drastic decrease of GABA in nIII and nIV in cat (Precht et al., 1973).

Another source for GABAergic afferent input to nIII and nIV is the INC. In monkey, tracer injections into nIV or rostral nIII resulted in retrograde labeling of medium-sized GABAergic neurons in the contralateral INC (Horn et al., 2003). This is in line with the recordings of monosynaptic inhibitory postsynaptic potentials in nIV and nIII after INC stimulation (Schwindt et al., 1974). Recent findings in cat confirm these results, and re-emphasize that premotor inhibitory neurons in INC may represent inhibitory burst neurons of the vertical saccadic system (Sugiuchi et al., 2013).

\section{OCULOMOTOR SUBGROUPS INVOLVED IN HORIZONTAL GAZE}

Aside from the CCN, the VEN, LAT, and DL subgroups in nIII receive a strong glycinergic input, as indicated by the relatively selective presence of GlyRs. In cat and monkey, glycinergic afferents were found to be associated specifically with motoneurons involved in horizontal eye movements, i.e., MR in nIII and lateral rectus muscle (LR) in the abducens nucleus (nVI). This is in contrast to the high concentration of GABAergic input to motoneurons for vertical eye movements in nIII and nIV (Spencer et al., 1989; Spencer and Baker, 1992). Tract-tracing experiments in monkey had shown that the MR is represented in two separated groups within nIII (Büttner-Ennever and Akert, 1981; Porter et al., 1983): the A-group occupying the ventral part of nIII and extending through its whole rostro-caudal extents, and the B-group forming a well separated DL group at caudal nIII levels (BüttnerEnnever and Akert, 1981). In addition at caudal levels, the MR population reaches as finger-like extensions into the fibers of the MLF, partly in conjunction with the A-group, partly forming completely separated islands. Based on the similar cytoarchitectural features and the selective glycinergic inputs, we consider the VEN group in human nIII as the homolog to the MR "A-group" in monkey, including the extensions of LAT into the surrounding MLF. Accordingly, the DL group is considered to be the homolog of the MR "B-group" (Figure 8): it has the same circular contour as in monkey, and a similar separation from the neighboring subgroups, with no motoneuronal dendrites extending beyond its boundaries. Interestingly, at the rostral nIII pole the dendrites of presumed MR motoneurons reach across the midline to their contralateral counterparts. Whether this is only the consequence of the disappearance of the NP at this level, or whether it has a functional background in the collection of common afferent inputs for controlling vergence, remains unclear.

The inhibitory control of horizontal gaze by glycinergic afferents that is seen for LR and MR motoneurons in cat and monkey is found to be preserved in the human as well (Spencer et al., 1989, 1992; Spencer and Baker, 1992). With anatomical, recording and pharmacological methods, the inhibitory nature of the glycinergic projection from the prepositus nucleus to the nVI has been demonstrated in the cat (Spencer et al., 1989). Up to date, the source of the glycinergic input to MR motoneurons in 
nIII is unknown. Although strychnine-sensitive GlyRs are known to mediate synaptic inhibition by activating chloride channels (Dutertre et al., 2012), glycine can also contribute to excitatory transmission by serving as an allosteric modulator for the glutamate N-methyl-D-aspartate receptor (Johnson and Ascher, 1987). Therefore, it is possible that the presence of GlyR seen in the MR subgroups in primates is associated with the glutamatergic inputs from the ipsilateral lateral vestibular nuclei via the ascending tract of Deiters (Nguyen and Spencer, 1999), which may contribute to viewing distance related gain changes of the vestibulo-ocular reflex (Snyder and King, 1992; Chen-Huang and McCrea, 1998).

However, in contrast to cat and monkey, in human all presumed MR subgroups receive an additional strong supply from GABAergic afferents, which even exceeds that of the motoneurons for vertical gaze. This finding is in line with observations from the human nVI, which also receives a strong GABAergic in addition to a strong glycinergic - input. This observation is, surprisingly, not the same as in monkey, where only a moderate GABAergic input is observed (Spencer and Baker, 1992; Waldvogel et al., 2010). Thereby, the GABAergic inputs provided the least useful marker to delineate the motoneuronal subgroups in human nIII, but at the same time they revealed an interesting and unusual neuroanatomical difference between monkey and man, which is seldom observed.

Although the GABA-immunoreactivity in the cat nVI is relatively weak, both motoneurons and internuclear neurons get some GABAergic input (de la Cruz et al., 1989). In cat 20\% of retrogradely labeled small internuclear neurons in and around the nIII expressed GABA-immunoreactivity (de la Cruz et al., 1992) and may be one source for the relatively weak GABAergic input to motoneurons and internuclear neurons in nVI (de la Cruz et al., 1992). In cat, tracer-labeled MR motoneurons receive a similar strong supply from glycinergic and GABAergic afferents (de la Cruz et al., 1992).

Up to date, it is generally accepted that horizontal conjugate eye movements are mediated through the nVI, which contains motoneurons and internuclear neurons. The motoneurons innervate the ipsilateral LR, the internuclear neurons activate the contralateral MR motoneurons in nIII via the MLF (for review: Horn and Leigh, 2011). A separate "extra-MLF” vergence pathway involving premotor neurons in the supraoculomotor area (SOA) with pure vergence signals (not conjugate eye movements) provides the command to move the eyes at equal magnitudes, but in opposite direction for alignment of gaze between targets at different depths (Mays, 1984). At the same location in the SOA, divergence neurons have been identified, which showed decreased firing rates with increasing vergence angles (Mays, 1984; Judge and Cumming, 1986). Direct inputs from the SOA to MR motoneurons have been demonstrated (Zhang et al., 1991), and they were shown to be related either to pure vergence or accommodation, or to both (Zhang et al., 1992). Theoretically, divergent eye movements require the activation of LR motoneurons and inhibition of MR motoneurons, which could be mediated through inhibition from GABAergic neurons in the SOA.

Another direct premotor input to motoneurons of the horizontal system was indicated from the central mesencephalic reticular formation (CMRF) after retrograde transsynaptic labeling studies in monkey applying rabies virus injections into LR (Ugolini et al., 2006; Büttner-Ennever, 2008). The CMRF is closely interconnected with the superior colliculus and the paramedian pontine reticular formation including the saccadic omnipause neurons (Cohen and Büttner-Ennever, 1984; Chen and May, 2000; Wang et al., 2013) and has been found to be correlated with horizontal and vertical saccades (Waitzman et al., 2000a,b, 2002). Preliminary data applying small biotin dextran injections into the rostromedial part of the CMRF in monkey revealed monosynaptic inputs to all MR motoneuron subgroups on both sides and pg neurons in the EWpg, indicating a role in vergence and the near triad, at least of this CMRF region (May et al., 2011; Horn et al., 2012). The accompanying ultrastructural analysis revealed that many of the tracer labeled terminals contacting MR motoneurons have features in accordance with inhibitory synapses, some of them expressing GABA-immunolabeling (May et al., 2011). To what extent the GABA-negative afferent terminals may represent glycinergic afferents remains to be studied. Based on the monkey data, the strong GABAergic input seen here in the human nIII may derive at least in part from the adjacent CMRF and/or SOA.

\section{GENERAL ORGANIZATION IN OCULOMOTOR NUCLEUS: PRIMATE}

The first anatomical description of the nIII is given by Stilling (1846). The partition into a dorsal and ventral portion, and the presence of numerous decussating axons was first described by von Gudden (1881; for review: Warwick, 1953a). A very precise description of the cytoarchitecture of the nIII was provided by Perlia on fetal human brain, which included the lateral and medial portion of the classical EW and the NP, which he originally had termed "Centralkern" (Perlia, 1889). Based on observations made after the removal of extraocular muscles in various species, different variations of an nIII map had been proposed (reviewed by Warwick, 1953a). The elaborate work of Warwick, who plotted the neurons undergoing chromatolysis after the resection of individual extraocular muscles in monkey, provided a map of the primate nIII, which was widely accepted and used as basis for the human nIII in many textbook illustrations (Warwick, 1953a). The organization of the motoneuronal groups shows a sequence from rostral to caudal of IR, MR, IO, SR, and LP motoneurons. The newly developed tract-tracing method basically confirmed the proposed arrangement of motoneuronal groups of individual muscles in the nIII of monkey, but it revealed for the first time the presence of two motoneuron groups for the MR, the ventral A-group and the DL circular B-group (Büttner-Ennever and Akert, 1981; Porter et al., 1983; Büttner-Ennever, 2006). This twofold representation of the MR within the nIII is most evident in primates and its function remains unclear (Augustine et al., 1981; Sun and May, 1993; Büttner-Ennever, 2006). So far no differences in histochemistry or afferent inputs have been found between the A- and B-group (Spencer et al., 1992; Wasicky et al., 2004; Erichsen et al., 2014).

It has been known for a long time that extraocular muscles exhibit a complex architecture consisting of a global and orbital layer. At least six different types of muscle fibers can be identified, which can be divided into two main categories of SIF and multiply-innervated non-twitch muscle fibers (MIF; for review: 
Spencer and Porter, 2006). Tract-tracing experiments in monkey revealed that the motoneurons of MIFs are located in the periphery of the motonuclei. For muscles innervated from the nIII the MIF motoneurons of IR and MR are located in the C-group DM to $\mathrm{NIII}$, and those of IO and SR in the S-group between the both nIII (Büttner-Ennever et al., 2001). Based on their different histochemical properties, SIF motoneurons were identified within nIII and putative MIF motoneurons have been identified around the medial aspects of nIII, also in human (Eberhorn etal., 2005, 2006). However, in the human nIII, the MIF motoneurons could not be allocated to specific extraocular muscles, yet (Horn et al., 2008). Therefore, the proposed map of the human nIII applies only to the SIF motoneurons within nIII, and has yet to be extended in future studies by the location of MIF motoneurons.

The exact knowledge of the location of the subgroups innervating individual eye muscles in human provides an important basis to localize lesions more accurately in MRI scans and relate it to clinical findings. Furthermore, the present work on transmitter inputs to individual eye muscle subgroups will form the basis for postmortem studies of afferent inputs to nIII in cases with known eye-movement deficits

\section{AUTHOR CONTRIBUTIONS}

Acquisition of data and analysis was performed by Emmanuel Che Ngwa, Christina Zeeh, and Ahmed Messoudi. Conception of the work was done by Anja K. E. Horn and Jean A. Büttner-Ennever. All authors contributed to the interpretation of data, preparation of the figures, and writing of the manuscript and approved the final version.

\section{ACKNOWLEDGMENTS}

This study is part of the medical doctoral thesis of Emmanuel Che Ngwa. The results are published with permission of the Medical Faculty of the Ludwig-Maximilians-University of Munich. We are very grateful to Christine Glombik and Laure Djaleu for their excellent technical assistance. Supported by Deutsche Forschungsgemeinschaft DFG HO 1639/4-3, BMBF (IFB-01EO0901, Brain-Net-01GI0505).

\section{REFERENCES}

Ahlfeld, J., Mustari, M., and Horn, A. K. E. (2011). Sources of calretinin inputs to motoneurons of extraocular muscles involved in upgaze. Ann. N. Y. Acad. Sci. 1233, 91-99. doi: 10.1111/j.1749-6632.2011.06168.x

Andressen, C., Blümcke, I., and Celio, M. R. (1993). Calcium-binding proteins - selective markers of nerve cells. Cell Tissue Res. 271, 181-208. doi: 10.1007/BF00318606

Augustine, J. R., Deschamps, E. G., and Ferguson, J. G. J. (1981). Functional organization of the oculomotor nucleus in the baboon. Am. J. Anat. 161, 393-403. doi: 10.1002/aja.1001610405

Averbuch-Heller, L. (1997). Neurology of the eyelids. Curr. Opin. Ophthalmol. 8, 27-34. doi: 10.1097/00055735-199712000-00005

Bachtell, R. K., Weitemier, A. Z., Galvan-Rosas, A., Tsivkovskaia, N. O., Risinger, F. O., Phillips, T. J., et al. (2003). The Edinger-Westphal-lateral septum urocortin pathway and its relation to alcohol-induced hypothermia. J. Neurosci. 23, 24772487.

Baer, K., Waldvogel, H. J., Faull, R. L. M., and Rees, M. I. (2009). Localization of glycine receptors in the human forebrain, brainstem, and cervical spinal cord: an immunohistochemical review. Front. Mol. Neurosci. 2:25. doi: 10.3389/neuro.02.025.2009
Baizer, J. S., and Baker, J. F. (2006). Immunoreactivity for calretinin and calbindin in the vestibular nuclear complex of the monkey. Exp. Brain Res. 172, 103-113. doi: 10.1007/s00221-005-0318-1

Baizer, J. S., and Broussard, D. M. (2010). Expression of calcium-binding proteins and nNOS in the human vestibular and precerebellar brainstem. J. Comp. Neurol. 518, 872-895. doi: 10.1002/cne.22250

Bernheimer, S. (1897). Experimentelle Studien zur Kenntniss der Innervation der inneren und äusseren vom Oculomotorius versorgten Muskeln des Auges. Albrecht Von Graefes Arch. Ophthalmol. 44, 481-525. doi: 10.1007/BF02017581

Bruce, G., Wainer, B. H., and Hersh, L. B. (1985). Immunoaffinity purification of human choline acetyltransferase: comparison of the brain and placental enzymes. J. Neurochem. 45, 611-620. doi: 10.1111/j.1471-4159.1985.tb04030.x

Burde, R. M. (1983). The visceral nuclei of the oculomotor complex. Trans. Am. Ophthalmol. Soc. 81, 532-548.

Burde, R. M. (1988). Direct parasympathetic pathway to the eye: revisited. Brain Res. 463, 158-162. doi: 10.1016/0006-8993(88)90540-9

Burde, R. M., and Williams, F. (1989). Parasympathetic nuclei. Brain Res. 498, 371-375. doi: 10.1016/0006-8993(89)91119-0

Büttner, U., Büttner-Ennever, J. A., and Henn, V. (1977). Vertical eye movement related unit activity in the rostral mesencephalic reticular formation of the alert monkey. Brain Res. 130, 239-252. doi: 10.1016/0006-8993(77)90273-6

Büttner-Ennever, J., and Horn, A. (eds). (2014). Olszewski and Baxter's Cytoarchitecture of the Human Brainstem, 3rd Edn. Basel: Karger.

Büttner-Ennever, J. A. (2006). The extraocular motor nuclei: organization and functional neuroanatomy. Prog. Brain Res. 151, 95-125. doi: 10.1016/S00796123(05)51004-5

Büttner-Ennever, J. A. (2008). Mapping the oculomotor system. Prog. Brain Res. 171, 3-11. doi: 10.1016/S0079-6123(08)00601-8

Büttner-Ennever, J. A., and Akert, K. (1981). Medial rectus subgroups of the oculomotor nucleus and their abducens internuclear input in the monkey. J. Comp. Neurol. 197, 17-27. doi: 10.1002/cne.901970103

Büttner-Ennever, J. A., Horn, A. K. E., Scherberger, H., and D'Ascanio, P. (2001). Motoneurons of twitch and nontwitch extraocular muscle fibers in the abducens, trochlear, and oculomotor nuclei of monkeys. J. Comp. Neurol. 438, 318-335. doi: $10.1002 / \mathrm{cne} .1318$

Chen, B., and May, P. J. (2000). The feedback circuit connecting the superior colliculus and central mesencephalic reticular formation: a direct morphological demonstration. Exp. Brain Res. 131, 10-21. doi: 10.1007/s002219900280

Chen, B., and May, P. J. (2002). Premotor circuits controlling eyelid movements in conjunction with vertical saccades in the cat: I. The rostral interstitial nucleus of the medial longitudinal fasciculus. J. Comp. Neurol. 450, 183-202. doi: $10.1002 /$ cne. 10313

Chen, B., and May, P. J. (2007). Premotor circuits controlling eyelid movements in conjunction with vertical saccades in the cat: II. Interstitial nucleus of Cajal. J. Comp. Neurol. 500, 676-692. doi: 10.1002/cne.21203

Chen-Huang, C., and McCrea, R. A. (1998). Viewing distance related sensory processing in the ascending tract of deiters vestibulo-ocular reflex pathway. J. Vest. Res. 8, 175-184. doi: 10.1016/S0957-4271(97)00001-3

Cohen, B., and Büttner-Ennever, J. A. (1984). Projections from the superior colliculus to a region of the central mesencephalic reticular formation (cMRF) associated with horizontal saccadic eye movements. Exp. Brain Res. 57, 167-176. doi: 10.1007/BF00231143

de la Cruz, R. R., Escudero, M., and Delgado-García, J. M. (1989). Behaviour of medial rectus motoneurons in the alert cat. Eur. J. Neurosci. 1, 288-295. doi: 10.1111/j.1460-9568.1989.tb00796.x

de la Cruz, R. R., Pastor, A. M., Martínez-Guijarro, F. J., López-García, C., and Delgado-García, J. M. (1992). Role of GABA in the extraocular motor nuclei of the cat: a postembedding immunocytochemical study. Neuroscience 51, 911-929. doi: 10.1016/0306-4522(92)90529-B

Dutertre, S., Becker, C.-M., and Betz, H. (2012). Inhibitory glycine receptors: an update. Biol. Chem. 287, 40216-40223. doi: 10.1074/jbc.R112.408229

Eberhorn, A. C., Ardelenanu, P., Büttner-Ennever, J. A., and Horn, A. K. E. (2005). Histochemical differences between motoneurons supplying multiply and singly innervated extraocular muscle fibers. J. Comp. Neurol. 491, 352-366. doi: $10.1002 /$ cne. 20715

Eberhorn, A. C., Büttner-Ennever, J. A., and Horn, A. K. E. (2006). Identification of motoneurons innervating multiply- or singly-innervated 
extraocular muscle fibres in the rat. Neuroscience 137, 891-903. doi: 10.1016/j.neuroscience.2005.10.038

Erichsen, J. T., Wright, N. F., and May, P. J. (2014). The morphology and ultrastructure of medial rectus subgroup motoneurons in the macaque monkey. J. Comp. Neurol. 522, 626-641. doi: 10.1002/cne.23437

Evinger, C. (1988). Extraocular motor nuclei: location, morphology and afferents. Rev. Oculomot. Res. 2, 81-117.

Fuchs, A. F., Becker, W., Ling, L., Langer, T. P., and Kaneko, C. R. (1992). Discharge patterns of levator palpebrae superioris motoneurons during vertical lid and eye movements in the monkey. J. Neurophysiol. 68, 233-243.

Fukushima, K., Kaneko, C. R., and Fuchs, A. F. (1992). The neuronal substrate of integration in the oculomotor system. Prog. Neurobiol. 39, 609-639. doi: 10.1016/0301-0082(92)90016-8

Gallyas, F. (1979). Silver staining of myelin by means of physical development. Neurol. Res. 1, 203-209.

Goldstein, M. E., Sternberger, N. H., and Sternberger, L. A. (1987). Phosphorylation protects neurofilaments against proteolysis. J. Neuroimmunol. 14, 149-160. doi: 10.1016/0165-5728(87)90049-X

Highstein, S. M., and Holstein, G. R. (2006). The anatomy of the vestibular nuclei. Prog. Brain Res. 151, 157-203. doi: 10.1016/S0079-6123(05)51006-9

Horn, A. K., and Büttner-Ennever, J. A. (2008). Brainstem circuits controlling lideye coordination in monkey. Prog. Brain Res. 171, 87-95. doi: 10.1016/S00796123(08)00612-2

Horn, A. K., Eberhorn, A., Härtig, W., Ardelenanu, P., Messoudi, A., and Büttner-Ennever, J. A. (2008). Perioculomotor cell groups in monkey and man defined by their histochemical and functional properties: reappraisal of the Edinger-Westphal nucleus. J. Comp. Neurol. 507, 1317-1335. doi: 10.1002/cne. 21598

Horn, A. K., and Leigh, R. J. (2011). The anatomy and physiology of the ocular motor system. Handb. Clin. Neurol. 102, 21-69. doi: 10.1016/B978-0-444-529039.00008-X

Horn, A. K. E., and Adamcyzk, C. (2011). "Reticular formation - eye movements, gaze and blinks," in Human Nervous System, 3rd Edn, eds G. Paxinos and J. K. Mai (San Diego: Academic Press), 328-366.

Horn, A. K. E., Bohlen, M. O., Warren, S., and May, P. J. (2012). Evidence for the central mesencephalic reticular formation playing a role in the near triad. Soc. Neurosci. Abstr. 373.12.

Horn, A. K. E., and Büttner-Ennever, J. A. (1998). Premotor neurons for vertical eye-movements in the rostral mesencephalon of monkey and man: the histological identification by parvalbumin immunostaining. J. Comp. Neurol. 392, 413-427. doi: 10.1002/(SICI)1096-9861(19980323)392:4<413::AID-CNE1>3.0. $\mathrm{CO} ; 2-3$

Horn, A. K. E., Büttner-Ennever, J. A., Gayde, M., and Messoudi, A. (2000). Neuroanatomical identification of mesencephalic premotor neurons coordinating eyelid with upgaze in the monkey and man. J. Comp. Neurol. 420, 19-34. doi: 10.1002/(SICI) 1096-9861(20000424)420:1<19::AID-CNE2>3.0 $\mathrm{CO} ; 2-\mathrm{D}$

Horn, A. K. E., Helmchen, C., and Wahle, P. (2003). GABAergic neurons in the rostral mesencephalon of the Macaque monkey that control vertical eye movements. Ann. N. Y. Acad. Sci. 1004, 19-28. doi: 10.1196/annals.1303.003

Ichikawa, T., and Shimizu, T. (1998). Organization of choline acetyltransferasecontaining structures in the cranial nerve motor nuclei and spinal cord of the monkey. Brain Res. 779, 96-103. doi: 10.1016/S0006-8993(97)01090-1

Ishikawa, S., Sekiya, H., and Kondo, Y. (1990). The center for controlling the near reflex in the midbrain of the monkey: a double labelling study. Brain Res. 519 , 217-222. doi: 10.1016/0006-8993(90)90080-U

Jiao, Y., Sun, Z., Lee, T., Fusco, F. R., Kimble, T. D., Meade, C. A., et al. (1999). A simple and sensitive antigen retrieval method for free-floating and slide-mounted tissue sections. J. Neurosci. Methods 93, 149-162. doi: 10.1016/S0165-0270(99)00142-9

Johnson, J. W., and Ascher, P. (1987). Glycine potentiates the NMDA response in cultured mouse brain neurons. Nature 325, 529-531. doi: 10.1038/325529a0

Judge, S. J., and Cumming, B. G. (1986). Neurons in the monkey midbrain with activity related to vergence eye movement and accommodation. J. Neurophysiol. 55, 915-930.

Kennard, C. (2011). Disorders of higher gaze control. Handb. Clin. Neurol. 102, 379-402. doi: 10.1016/B978-0-444-52903-9.00020-0
Kozicz, T., Bittencourt, J. C., May, P. J., Reiner, A., Gamlin, P. D. R., Palkovits, M., et al. (2011). The Edinger-Westphal nucleus: a historical, structural, and functional perspective on a dichotomous terminology. J. Comp. Neurol. 519, 1413-1434. doi: 10.1002/cne.22580

Leigh, R. J., and Zee, D. S. (2006). The Neurology of Eye Movements. New York: Oxford University Press.

May, P. J., Horn, A. K. E., Mustari, M. J., and Warren, S. (2011). Central mesencephalic reticular formation projections onto oculomotor motoneurons. Soc. Neurosci. Abstr. 699.01

May, P. J., Reiner, A. J., and Ryabinin, A. E. (2008). Comparison of the distributions of urocortin-containing and cholinergic neurons in the perioculomotor midbrain of the cat and macaque. J. Comp. Neurol. 507, 1300-1316. doi: 10.1002/cne. 21514

May, P. J., Vidal, P.-P., Baker, H., and Baker, R. (2012). Physiological and anatomical evidence for an inhibitory trigemino-oculomotor pathway in the cat. J. Comp. Neurol. 520, 2218-2240. doi: 10.1002/cne.23039

Mays, L. E. (1984). Neural control of vergence eye movements: convergence and divergence neurons in midbrain. J. Neurophysiol. 51, 1091-1108.

Nguyen, L. T., and Spencer, R. F. (1999). Abducens internuclear and ascending tract of Deiters inputs to medial rectus motoneurons in the cat oculomotor nucleus: neurotransmitters. J. Comp. Neurol. 411, 73-86. doi: 10.1002/(SICI)10969861(19990816)411:1<73::AID-CNE6>3.0.CO;2-7

Obata, K., and Highstein, S. M. (1970). Blocking by picrotoxin of both vestibular inhibition and GABA action on rabbit oculomotor neurones. Brain Res. 18, 538541. doi: 10.1016/0006-8993(70)90136-8

Olszewski, J., and Baxter, D. (1982). Cytoarchitecture of the Human Brain Stem, 2nd Edn. Basel: Karger.

Panegrossi, G. (1898). Contributo allo studio anatomo-fisiologico dei centri dei nerve oculomotori dell'uomo. Ric. Lab. Anat. norm. Univ. Roma 6, 103-155.

Partsalis, A. M., Zhang, Y., and Highstein, S. M. (1995). Dorsal Y group in the squirrel monkey. I. Neuronal responses during rapid and long-term modifications of the vertical VOR. J. Neurophysiol. 73, 615-631.

Pearson, A. A. (1943). Trochlear nerve in human fetuses. J. Comp. Neurol. 78, 29-43. doi: 10.1002/cne.900780103

Perlia, D. (1889). Die Anatomie des Oculomotoriuscentrums beim Menschen. Albrecht von Graefes Arch. Ophthalmol. 35, 287-308. doi: 10.1007/BF01695201

Pfeiffer, F., Simler, R., Grenningloh, G., and Betz, H. (1984). Monoclonal antibodies and peptide mapping reveal structural similarities between the subunits of the glycine receptor of rat spinal cord. Proc. Natl. Acad. Sci. U.S.A. 81, 7224-7227. doi: 10.1073/pnas.81.22.7224

Porter, J. D., Burns, L. A., and May, P. J. (1989). Morphological substrate for eyelid movements: innervation and structure of primate levator palpebrae superioris and orbicularis oculi muscles. J. Comp. Neurol. 287, 64-81. doi: $10.1002 /$ cne.902870106

Porter, J. D., Guthrie, B. L., and Sparks, D. L. (1983). Innervation of monkey extraocular muscles: localization of sensory and motor neurons by retrograde transport of horseradish peroxidase. J. Comp. Neurol. 218, 208-219. doi: 10.1002/cne.902180208

Precht, W., Baker, R., and Okada, Y. (1973). Evidence for GABA as the synaptic transmitter of the inhibitory vestibulo-ocular pathway. Exp. Brain Res. 18, 415428. doi: 10.1007/BF00239109

Ryabinin, A. E., Tsivkovskaia, N. O., and Ryabinin, S. A. (2005). Urocortin 1-containing neurons in the human Edinger-Westphal nucleus. Neuroscience 134, 1317-1323. doi: 10.1016/j.neuroscience.2005.05.042

Schmidtke, K., and Büttner-Ennever, J. A. (1992). Nervous control of eyelid function - a review of clinical, experimental and pathological data. Brain 115, 227-247. doi: 10.1093/brain/115.1.227

Schwindt, P. C., Precht, W., and Richter, A. (1974). Monosynaptic excitatory and inhibitory pathways from medial midbrain nuclei to trochlear motoneurons. Exp. Brain Res. 20, 223-238. doi: 10.1007/BF00238314

Sekiya, H., Kojima, Y., Hiramoto, D., Mukuno, K., and Ishikawa, S. (1992). Bilateral innervation of the musculus levator palpebrae superioris by single motoneurons in the monkey. Neurosci. Lett. 146, 10-12. doi: 10.1016/0304-3940(92) 90159-5

Snyder, L. H., and King, W. M. (1992). Effect of viewing distance and location of the axis of head rotation on the monkey's vestibuloocular reflex. I. Eye movement responses. J. Neurophysiol. 67, 861-874. 
Spencer, R. F., and Baker, R. (1992). GABA and glycine as inhibitory neurotransmitters in the vestibulo-ocular reflex. Ann. N. Y. Acad. Sci. 656, 602-611. doi: 10.1111/j.1749-6632.1992.tb25239.x

Spencer, R. F., and Porter, J. D. (1981). Innervation and structure of extraocular muscles in the monkey in comparison to those of the cat. J. Comp. Neurol. 198, 649-665. doi: 10.1002/cne.901980407

Spencer, R. F., and Porter, J. D. (2006). Biological organization of the extraocular muscles. Prog. Brain Res. 151, 43-80. doi: 10.1016/S0079-6123(05)51002-1

Spencer, R. F., Wang, S. F., and Baker, R. (1992). The pathways and functions of GABA in the oculomotor system. Prog. Brain Res. 90, 307-331. doi: 10.1016/S0079-6123(08)63620-1

Spencer, R. F., Wenthold, R. J., and Baker, R. (1989). Evidence for glycine as an inhibitory neurotransmitter of vestibular, reticular, and prepositus hypoglossi neurons that project to the cat abducens nucleus. J. Neurosci. 9, 2718-2736.

Sternberger, L. A., Harwell, L. W., and Sternberger, N. H. (1982). Neurotype: regional individuality in rat brain detected by immunocytochemistry with monoclonal antibodies. Proc. Natl. Acad. Sci. U.S.A. 79, 1326-1330. doi 10.1073/pnas.79.4.1326

Sternberger, L. A., and Sternberger, N. H. (1983). Monoclonal antibodies distinguish phorphorylated and non-phosphorylated forms of neurofilaments in situ. Proc. Natl. Acad. Sci. U.S.A. 80, 6126-6130. doi: 10.1073/pnas.80.19.6126

Stilling, B. (1846). Disquisitiones de structure et functionibus cerebri. Jenae: sumt. F. Maukii. T. 1, 36.

Sugiuchi, Y., Takahashi, M., and Shinoda, Y. (2013). Input-output organization of inhibitory neurons in the interstitial nucleus of Cajal projecting to the contralateral trochlear and oculomotor nucleus. J. Neurophysiol. 110, 640-657. doi: 10.1152/jn.01045.2012

Sun, W. S., and May, P. J. (1993). Organization of the extraocular and preganglionic motoneurons supplying the orbit in the lesser galago. Anat. Rec. 237, 89-103. doi: 10.1002/ar.1092370109

Triller, A., Cluzeaud, F., Pfeiffer, F., Betz, H., and Korn, H. (1985). Distribution of glycine receptors at central synapses: an immunoelectron microscopy study. $J$. Cell Biol. 101, 683-688. doi: 10.1083/jcb.101.2.683

Tsuchida, U. (1906). Ueber die Ursprungskerne der Augenbeweguns-Nerven im Mittel- und Zwischenhirn. Arb. Hirnanat. Inst. Zürich 1-2, 1-205.

Ugolini, G., Klam, F., Doldan Dans, M., Dubayle, D., Brandi, A.-M., BüttnerEnnever, J. A., et al. (2006). Horizontal eye movement networks in primates as revealed by retrograde transneuronal transfer of rabies virus: differences in monosynaptic input to "slow" and "fast" abducens motoneurons. J. Comp. Neurol. 498, 762-785. doi: 10.1002/cne.21092

Van der Werf, F., Aramideh, M., Ongerboer De Visser, B. W., Baljet, B., Speelman, J. D., and Otto, J. A. (1997). A retrograde double fluorescent tracing study of the levator palpebrae superioris muscle in the cynomolgus monkey. Exp. Brain Res. 113, 174-179. doi: 10.1007/BF02454155

von Gudden, B. (1881). Über den Tractus peduncularis transversus. Arch. Psychiatr. Nervenkr. 2, 364-366.

Waitzman, D. M., Pathmanathan, J., Presnell, R., Ayers, A. S., and Depalma-Bowles, S. (2002). Contribution of the superior colliculus and the mesencephalic reticular formation to gaze control. Ann. N. Y. Acad. Sci. 956, 111-129. doi: 10.1111/j.17496632.2002.tb02813.x

Waitzman, D. M., Silakov, V. L., Depalma-Bowles, S., and Ayers, A. S. (2000a). Effects of reversible inactivation of the primate mesencephalic reticular formation. I. Hypermetric goal-directed saccades. J. Neurophysiol. 83, 2260-2284.

Waitzman, D. M., Silakov, V. L., Depalma-Bowles, S., and Ayers, A. S. (2000b). Effects of reversible inactivation of the primate mesencephalic reticular formation. II. Hypometric vertical saccades. J. Neurophysiol. 83, 2285-2299.
Waldvogel, H. J., Baer, K., Eady, E., Allen, K. L., Gilbert, R. T., Mohler, H., et al. (2010). Differential localization of $\gamma$-aminobutyric acid type a and glycine receptor subunits and gephyrin in the human pons, medulla oblongata and uppermost cervical segment of the spinal cord: an immunohistochemical study. J. Comp. Neurol. 518, 305-328. doi: 10.1002/cne.22212

Wang, N., Perkins, E., Zhou, L., Warren, S., and May, P. J. (2013). Anatomical evidence that the superior colliculus controls saccades through central mesencephalic reticular formation gating of omnipause neuron activity. J. Neurosci. 33, 16285-16296. doi: 10.1523/JNEUROSCI.2726-11.2013

Warwick, R. (1953a). Representation of the extraocular muscles in the oculomotor nuclei of the monkey. J. Comp. Neurol. 98, 449-495. doi: 10.1002/cne.9009 80305

Warwick, B. (1953b). The identity of the posterior dorso-central nucleus of Panegrossi. J. Comp. Neurol. 99, 599-611. doi: 10.1002/cne.900990307

Warwick, R. (1955). The so-called nucleus of convergence. Brain 78, 92-114. doi: 10.1093/brain/78.1.92

Wasicky, R., Horn, A. K. E., and Büttner-Ennever, J. A. (2004). Twitch and nontwitch motoneuron subgroups of the medial rectus muscle in the oculomotor nucleus of monkeys receive different afferent projections. J. Comp. Neurol. 479, 117-129. doi: 10.1002/cne.20296

Wentzel, P. R., Gerrits, N. M., and Dezeeuw, C. I. (1996). GABAergic and glycinergic inputs to the rabbit oculomotor nucleus with special emphasis on the medial rectus subdivision. Brain Res. 707, 314-319. doi: 10.1016/0006-8993(95) 01389-X

Zeeh, C., Hess, B. J., and Horn, A. K. E. (2013). Calretinin inputs are confined to motoneurons for upward eye movements in monkey. J. Comp. Neurol. 521, 3154-3166. doi: 10.1002/cne.23337

Zhang, Y., Gamlin, P. D. R., and Mays, L. E. (1991). Antidromic identification of midbrain near response cells projecting to the oculomotor nucleus. Exp. Brain Res. 84, 525-528. doi: 10.1007/BF00230964

Zhang, Y., Mays, L. E., and Gamlin, P. D. R. (1992). Characteristics of near response cells projecting to the oculomotor nucleus. J. Neurophysiol. 67, 944-960.

Ziegler, B., Augstein, A., Schröder, D., Mauch, L., Hahmann, J., Schlosser, M., et al. (1996). Glutamate decarboxylase (GAD) is not detectable on the surface of rat islet cells examined by cytofluorometry and complement-dependent antibodymediated cytotoxicity of monoclonal GAD antibodies. Horm. Metab. Res. 28, 11-15. doi: 10.1055/s-2007-979121

Conflict of Interest Statement: The authors declare that the research was conducted in the absence of any commercial or financial relationships that could be construed as a potential conflict of interest.

Received: 16 November 2013; accepted: 14 January 2014; published online: 12 February 2014.

Citation: Che Ngwa E, Zeeh C, Messoudi A, Büttner-Ennever JA and Horn AKE (2014) Delineation of motoneuron subgroups supplying individual eye muscles in the human oculomotor nucleus. Front. Neuroanat. 8:2. doi: 10.3389/fnana.2014.00002

This article was submitted to the journal Frontiers in Neuroanatomy. Copyright (C) 2014 Che Ngwa, Zeeh, Messoudi, Büttner-Ennever and Horn. This is an open-access article distributed under the terms of the Creative Commons Attribution License (CC BY). The use, distribution or reproduction in other forums is permitted, provided the original author(s) or licensor are credited and that the original publication in this journal is cited, in accordance with accepted academic practice. No use, distribution or reproduction is permitted which does not comply with these terms. 